\title{
Epidermal Growth Factor Represses Constitutive Androstane Receptor Expression in Primary Human Hepatocytes and Favors Regulation by Pregnane X Receptor
}

\author{
Hugues de Boussac, Claire Gondeau, Philippe Briolotti, Cédric Duret, Fridolin Treindl, \\ Michael Römer, Jean-Michel Fabre, Astrid Herrero, Jeanne Ramos, Patrick Maurel, \\ Markus Templin, Sabine Gerbal-Chaloin, ${ }^{1}$ and Martine Daujat-Chavanieu ${ }^{1}$
}

IRMB, INSERM, University Montpellier, Montpellier, France (H.d.B., C.G., P.B., C.D., P.M., S.G.-C., M.D.-C.); CHU Montpellier, IRMB, Montpellier, France (C.G., C.D., M.D.-C.); Natural and Medical Sciences Institute, University of Tübingen, Reutlingen, Germany (F.T., M.T.); Centre of Bioinformatics Tübingen (ZBIT), University of Tübingen, Tübingen, Germany (M.R.); Department of Digestive Surgery, Hospital Saint Eloi, CHU Montpellier, Montpellier, France (J.-M.F.); Departments of General Surgery, Division of Transplantation, College of Medicine, University of Montpellier, Montpellier, France (A.H.); and Pathological Anatomy Department, Hospital Guy de Chauliac, CHU Montpellier, Montpellier, France (J.R.)

Received September 19, 2017; accepted December 14, 2017

\section{ABSTRACT}

Growth factors have key roles in liver physiology and pathology, particularly by promoting cell proliferation and growth. Recently, it has been shown that in mouse hepatocytes, epidermal growth factor receptor (EGFR) plays a crucial role in the activation of the xenosensor constitutive androstane receptor (CAR) by the antiepileptic drug phenobarbital. Due to the species selectivity of CAR signaling, here we investigated epidermal growth factor (EGF) role in CAR signaling in primary human hepatocytes. Primary human hepatocytes were incubated with CITCO, a human CAR agonist, or with phenobarbital, an indirect CAR activator, in the presence or absence of EGF. CARdependent gene expression modulation and PXR involvement in these responses were assessed upon siRNA-based silencing of the genes that encode CAR and PXR. EGF significantly reduced CAR expression and prevented gene induction by CITCO and, to a lower extent, by phenobarbital. In the absence of EGF, phenobarbital and CITCO modulated the expression of 144 and 111 genes, respectively, in primary human hepatocytes. Among these genes, only 15 were regulated by CITCO and one by phenobarbital in a CAR-dependent manner. Conversely, in the presence of EGF, CITCO and phenobarbital modulated gene expression only in a CAR-independent and PXRdependent manner. Overall, our findings suggest that in primary human hepatocytes, EGF suppresses specifically CAR signaling mainly through transcriptional regulation and drives the xenobiotic response toward a pregnane $X$ receptor (PXR)-mediated mechanism.

\section{Introduction}

Liver is a metabolically active organ that biotransforms a myriad of exogenous and endogenous compounds essentially through the metabolic functions of hepatocytes. These activities are finely regulated by a coordinated network of transcription factors. Among them, two nuclear receptors are known to control the expression of key detoxication enzymes: pregnane $\mathrm{X}$ receptor (NR1I2) and constitutive androstane receptor (CAR, NR1I3) (Wang et al., 2012). They may also participate in cancer development and drug resistance (De Mattia et al., 2016). Moreover, increasing evidence indicates that they modulate numerous endogenous signals and crosstalk with signaling pathways involved in the regulation of the homeostasis of bile acids, lipids, hormones, glucose, inflammation, vitamins, and other endobiotics (Wagner et al., 2005;

The research leading to these results received funding from the Innovative Medicine Initiative Joint Undertaking (IMI JU) under grant agreement $\mathrm{n}^{\circ} 115001$ (MARCAR project).

${ }^{1}$ S.G.-C. and M.D.-C. are coauthors.

https://doi.org/10.1124/dmd.117.078683.
Pascussi et al., 2008; Wada et al., 2009). PXR activation may worsen steatosis, obesity, and insulin resistance (Zhou et al., 2006, 2008; Li et al., 2012). Conversely, CAR activation is often described as beneficial, because it allows maintaining the homeostasis of cholesterol and bile acids and reducing blood glucose and steatosis. However, CAR effect on lipid metabolism was not reproduced in human primary hepatocytes (Lynch et al., 2014).

Considering the central role of CAR and PXR in transforming xenobiotics and regulating cell metabolism, much research has focused on the identification and development of molecules to modulate their activities. However, the study of PXR and CAR function is hindered by several factors. Indeed, the crosstalk between CAR and PXR through recognition of common responsive elements triggers the reciprocal activation of overlapping target genes that coordinate the hepatic response (Xie et al., 2000). For instance, $C Y P 2 B 6$ is a target of human CAR, but can be also efficiently induced by rifampicin (RIF), a specific PXR activator (Goodwin et al., 2001). Similarly CAR can regulate $C Y P 3 A 4$, the prototypical PXR target gene (Maglich et al., 2002). Moreover, CAR and PXR

ABBREVIATIONS: CAR, constitutive androstane receptor; CITCO, 6-(4-chlorophenyl)imidazo[2,1-b][1,3]thiazole-5-carbaldehyde O-(3,4-dichlorobenzyl) oxime; CYP, cytochrome P450; EGF, epidermal growth factor; EGFR, epidermal growth factor receptor; FC, fold change; KEGG, Kyoto Encyclopedia for Genes and Genomes; PB, phenobarbital; PCR, polymerase chain reaction; PHH, primary human hepatocytes; qPCR, quantitative polymerase chain reaction; PXR, pregnane $X$ receptor; RIF, rifampicin; UT, untreated. 
operate as heterodimers with retinoic $\mathrm{X}$ receptor $(\mathrm{RXR}, \mathrm{NR} 2 \mathrm{~B} 1)$ and share coactivators, such as SRC- 1 and PGC- $1 \alpha$, and corepressors, such as SMRT and NCoR (Oladimeji et al., 2016). It is therefore challenging to identify human CAR-specific functions and target genes.

Species-specific direct CAR agonists have been found, such as 6-(4-chlorophenyl)imidazo[2,1-b][1,3]thiazole-5-carbaldehyde $O$-(3,4-dichlorobenzyl) oxime (CITCO) (Maglich et al., 2003) for human CAR and 1,4-bis-[2-(3,5-dichloropyridyloxy)]benzene, 3,3',5,5'-tetrachloro1,4-bis(pyridyloxy) benzene (TCBOBOP) (Tzameli et al., 2000) for mouse CAR. Conversely, phenobarbital (PB) is an indirect CAR activator that does not directly interact with the CAR ligand binding domain and thus does not show species specificity. Pregnenolone $16 \alpha-$ carbonitrile specifically activates mouse PXR, whereas the antibiotic RIF activates human, but not mouse, PXR. Human PXR can also be activated by $\mathrm{PB}$ via a receptor binding mechanism, in contrast to the receptor binding-independent mechanism involved in $\mathrm{PB}$-mediated CAR activation (Moore et al., 2000). CAR activation by PB is the key molecular initiating event and promotes hepatocarcinogenesis in rodents. No carcinogenic effect of PB has been reported in humans (Elcombe et al., 2014).

Accumulating evidences indicate that xenobiotic metabolism is repressed during hepatic regeneration and cancer. This stimulated investigations on the involvement of growth factors and cytokines in the downregulation of CYP enzymes because of their important role in liver regeneration and diseases (Berasain and Avila, 2014). For instance, EGF represses $C Y P 2 B$ gene induction by $\mathrm{PB}$ in mouse and rat hepatocytes (Kawamura et al., 1999; Koike et al., 2007). Moreover, EGF-mediated $C Y P 2 B 6$ inhibition in human hepatocytes is accompanied by a strong decrease of $C A R$ mRNA expression (Bachleda et al., 2009). The recent finding of a crosstalk between CAR and EGFR (Mutoh et al., 2013) further highlights the connection between cell proliferation/survival and liver detoxification/metabolism. Early and recent studies demonstrated that $\mathrm{PB}$ activates CAR transcriptional activity by preventing EGFR phosphorylation (Mutoh et al., 2009; Negishi, 2017). Very recently, it was found that EGF stimulates CAR homodimerization, thus forcing CAR in its inactive form (Shizu et al., 2017). Indeed, CAR activation by CAR ligands (CITCO) and indirect activators (PB) is regulated through homodimer-monomer conversion (Shizu et al., 2017). Moreover, PB competes with EGF for binding to EGFR in human cell lines and mouse hepatocytes (Mutoh et al., 2013).

To date EGF impact on CAR signaling has not been studied in primary human hepatocytes (PHHs). This model presents advantages over human liver cell lines, such as the physiological expression of transcription factors and coregulatory molecules and human CAR localization in the cytoplasm. We investigated EGF effect on CAR transcriptional activity in PHHs, using the human CAR agonist CITCO and the indirect human CAR activator PB. We also downregulated CAR with specific siRNAs to identify specific targets/responses. We found that EGF reduced transcription of CAR target genes, as expected, and also decreased CAR, but not PXR expression. EGF greatly influenced $\mathrm{PHH}$ response to direct (CITCO) or indirect $(\mathrm{PB})$ activators and prevented CAR-dependent gene expression. Finally, we demonstrated that in the presence of EGF, CAR target genes are not regulated by PB via CAR, but via PXR.

\section{Materials and Methods}

Primary Human Hepatocyte Isolation and Culture. PHHs were provided by Biopredic International (Rennes, France), or isolated, as described previously (Pichard et al., 2006), from donor organs unsuitable for transplantation or from liver resections performed in adult patients for medical reasons unrelated to our research program. Liver samples were obtained from the Biologic Resource Center of Montpellier University Hospital (CRB-CHUM; http://www.chumontpellier.fr; Biobank ID: BB-0033-00031), and this study benefitted from the expertise of Dr Jeanne Ramos (hepatogastroenterology sample collection) and Prof Sylvain Lehmann (CRB-CHUM manager). The patients' clinical characteristics are presented in Table 1. The procedure was approved by the French Ethics Committee and written or oral consent was obtained from the patients or their families.

PHHs were seeded at confluency $\left(4.10^{5}\right.$ cells/well) in collagen-coated 24 -well dishes and cultured in $5 \% \mathrm{CO}_{2}$ humidified atmosphere at $37^{\circ} \mathrm{C}$ in hepatocyte growth medium (WME medium supplemented with $5 \mu \mathrm{g} / \mathrm{ml}$ insulin, $0.1 \mu \mathrm{M}$ hydrocortisone, $10 \mu \mathrm{g} / \mathrm{ml}$ transferrin, $250 \mu \mathrm{g} / \mathrm{ml}$ ascorbic acid, $3.75 \mathrm{mg} / \mathrm{ml}$ fatty acid-free bovine serum albumin, $2 \mathrm{mM}$ glutamine, penicillin and streptomycin). When indicated, hepatocyte growth medium was supplemented with $10 \mathrm{ng} / \mathrm{ml}$ EGF (Peprotech, Neuilly-Sur-Seine, France) (Ismail et al., 1991; Katsura et al., 2002).

siRNA Transfection. Adherent PHHs were transfected with $10 \mathrm{nM}$ scrambled SiRNA (siCT) or ON-TARGET plus SMARTpool siRNAs (pool of four siRNAs) specific for human NR1I3 (the gene encoding CAR) or human NR1I2 (the gene encoding PXR) (Dharmacon, Lafayette, CO) using Lipofectamine RNAiMAX (Life Technologies, Carlsbad, CA) at days 2 and 5 after seeding. At day 5 postseeding, $\mathrm{PHH}$ were incubated with $0.5 \mathrm{mM} \mathrm{PB}, 1 \mu \mathrm{M}$ CITCO, $10 \mu \mathrm{M}$ RIF (Sigma, St. Louis, MO), or vehicle (dimethylsulfoxide) for 24 hours.

RNA Isolation and Quantitative PCR. RNA was extracted using the TRIzol reagent (Invitrogen/Life Technologies), and then $300 \mathrm{ng}$ of total RNA was reverse transcribed (RT) using the high-capacity cDNA reverse transcription kit (Applied Biosystems, Foster City, CA). Quantitative PCR (qPCR) was performed using the Roche SYBER Green reagent and a LightCycler 480 apparatus (Roche Diagnostic, Meylan, France) with the following program: one step at $95^{\circ} \mathrm{C}$ for 10 minutes and then 50 cycles of denaturation at $95^{\circ} \mathrm{C}$ for 10 seconds, annealing at $65^{\circ} \mathrm{C}$ for 15 seconds, and elongation at $72^{\circ} \mathrm{C}$ for 15 seconds. The primer sequences are listed in Table 2.

Microarray Data Acquisition. Total RNA (500 ng) was amplified and labeled for hybridization on GeneChip HT HG-U133+ PM Array plates. Data were acquired following the manufacturer's instructions (Affymetrix, High Wycombe, UK). For each condition, five biologic replicates were used. To obtain the intensity value signal, scanned plates were processed using the Affymetrix GCOS 1.4 software, and the Affymetrix CEL files were normalized using the Robust Multichip Average (RMA) implementation of the algorithm. The raw microarray data in .CEL files are available in the Gene Expression Omnibus with accession number GSE68493 at http://www.ncbi.nlm.nih.gov/geo/.

Microarray Data Analysis. Microarray data were analyzed using the web tool Genomicscape (genomicscape.com) (Kassambara et al., 2015). Briefly, paired significance analysis of microarrays was performed using the 15,000 probe sets with the highest S.D. Significance was calculated using the Wilcoxon test and the list of significantly deregulated genes (fold change, FC, $>1.3$; false discovery rate $<5 \%$ ) was extracted. Venn diagrams were generated using the Venny tool (http://bioinfogp.cnb.csic.es/tools/venny/index.html). Heat maps of the identified genes of interest were produced using Cluster 3.0 and Treeview. Finally, pathway

TABLE 1

Liver donor data

\begin{tabular}{llccl}
\hline Liver & \multicolumn{1}{c}{ Origin } & Age $(\mathrm{yr})$ & Sex & \multicolumn{1}{c}{ Pathology } \\
\hline Liv1 & Donor & 41 & M & Anoxia \\
Liv2 & Biopredic Intl & 78 & F & Hepatocellular carcinoma \\
Liv3 & Resection & 66 & F & Metastasis from colon cancer \\
Liv4 & Donor & 69 & F & Renal cyst \\
Liv5 & Donor & 53 & M & Stroke \\
Liv6 & Resection & 76 & M & Metastasis from colon cancer \\
Liv7 & Resection & 45 & F & Polycystic liver disease \\
Liv10 & Biopredic Intl & 72 & M & Hepatocellular carcinoma \\
Liv12 & Resection & 78 & F & Cholangiocarcinoma \\
Liv13 & Donor & 59 & M & Meningeal hemorrhage \\
Liv14 & Donor & 60 & M & Stroke \\
Liv15 & Donor & 55 & M & Stroke \\
Liv16 & Resection & 67 & F & Metastasis from colon cancer \\
& & & & \\
\hline
\end{tabular}


TABLE 2

Primer sequences

\begin{tabular}{lll}
\hline \multicolumn{1}{c}{ Gene } & \multicolumn{1}{c}{ Forward Primer } & \multicolumn{1}{c}{ Reverse Primer } \\
\hline ALAS1 & GATGTCAGCCACCTCAGAGAAC & CATCCACGAAGGTGATTGCTCC \\
CAR & TGCTGCCTCTGGTCACACAC & CCCGCAGAGGAAGTTTGTG \\
CPEB3 & GGTGTTTGTTGAGGACTTCCTC & CCTCTTGGAACAGCAGAAAGGC \\
CYP2A6 & GTCAATCTCCTCATGGACCTTGG & CCTGGTGATGACCACGTTGAAC \\
CYP2A7 & CGCTATGGCTTCTTGCTGCTCA & CTCCATGTAGGGCATCTTGGTC \\
CYP2B6 & ATGGGGCACTGAAAAAGACTGA & AGAGGCGGGGACACTGATGAC \\
CYP2C8 & GAGACAACAAGCACCACTCTGAG & CAGTGTAAGGCATGTGGCTCCT \\
CYP2C9 & TCCTATCATTGATTACTTCCCG & AACTGCAGTGTTTCCAAGC \\
CYP3A4 & GCCTGGTGCTCCTCTATCTA & GGTGTTGACCATCATAAAG \\
CYP3A43 & CTGCCTATGACACAACTAGCACC & TACCAGGGCATCGTAGGTGACA \\
CYP3A7 & AAGTCTGGGGTATTTATGACT & CGCTGGTGATGTTGGAGAC \\
EPHX1 & GTTTTCCACCTGGACCAATACGG & TGGTGCCTGTTGTCCAGTAGAG \\
POR & ACTCTGCTCTCGTCAACCAGCT & TGGGTGCTTCTTGTTGGACTCC \\
PXR & GGACCAGCTGCAGGAGCAAT & CATGAGGGGCGTAGCAAAGG \\
RDH16 & TATGGCGTGGAAGCCTTCTCTG & GGTCCCAAACTCCAGGAAGCT \\
RPLP0 & TCGACAATGGCAGCATCTAC & GCCTTGACCTTTCAGCAAG \\
STEAP2 & CCTCTGCTTACCGATGAGAAGG & CAGGAGGGAAAGTAAGCCAAGG \\
TAGLN & TCCAGGTCTGGCTGAAGAATGG & CTGCTCCATCTGCTTGAAGACC \\
TSKU & AGTCGCTTGACCTCAGCCACAA & TCGTGAAGGCAGACACTGAGAC \\
\hline
\end{tabular}

enrichment was assessed using KEGG [Kyoto Encyclopedia for Genes and Genomes (KEGG)] and the STRING web tool (http://string-db.org).

Protein Analysis. Total proteins were extracted from PHH cultures using RIPA lysis buffer supplemented with a protease inhibitor cocktail (Santa Cruz Biotechnology, Santa Cruz, CA). Protein concentration was determined using the bicinchoninic acid method, according to the manufacturer's instructions (Pierce Chemical, Rockford, IL). Proteins ( $20 \mu \mathrm{g} / \mathrm{sample}$ ) were resolved on $10 \%$ Precast SDS-polyacrylamide gels (Bio-Rad Laboratories, Marnes la Coquette, France) and transferred to polyvinylidene fluoride membranes (Bio-Rad Laboratories). Membranes were incubated with antibodies against CYP2B6 and GAPDH (sc67224 and sc-32233; Santa Cruz Biotechnology). Immunocomplexes were detected with a horseradish peroxidase-conjugated mouse secondary antibody (Sigma) followed by enhanced chemiluminescence (Millipore, Molsheim, France). Signals were acquired using a ChemiDoc-XRS+ apparatus (Bio-Rad Laboratories) and quantified with the Image Laboratory software (version 4.1)

DigiWest. The NuPAGE SDS-PAGE gel system (Life Technologies) was used for protein separation and blotting. Proteins (18 $\mu \mathrm{g}$ per sample) were separated using $4 \%-12 \%$ Bis-Tris gels according to the manufacturer's instructions. Blotting onto PVDF membranes (Millipore) was performed in standard conditions. For high content Western blot analysis, the DigiWest procedure was performed as described (Treindl et al., 2016).

Statistical Analysis. Quantitative PCR results were expressed as the mean \pm S.E.M. Results were compared using the paired $t$ test. Differences were considered statistically significant when $P<0.05$.

\section{Results}

EGF Strongly Affects Gene Expression in PHHs. First, the EGFR pathway activity in PHHs was monitored after long-term incubation (from day 0 to day 5) with $10 \mathrm{ng} / \mathrm{ml}$ EGF. Phosphorylation of ERK1/2 (at T202 and Y204), of MEK1/2 (at S217 and S221) and of the immediate downstream kinase RSK1 (p90RSK T573) demonstrated the sustained activation of the EGFR pathway upon incubation with the ligand (Fig. 1A).

Then, a global transcriptome analysis was performed in PHHs incubated or not with EGF for the same period (day 0 to day 5). Compared with control PHHs (without EGF), 328 genes (187 upregulated and 141 downregulated) were deregulated in EGF-treated cultures. KEGG pathway enrichment analysis revealed the contribution of the differentially expressed genes to specific biologic processes. Genes upregulated following EGF incubation were mostly classified in 14 KEGG pathways mainly associated with cell proliferation and cancer (Komposch and Sibilia, 2015) (Fig. 1B). Conversely, genes downregulated upon incubation with EGF belonged mostly to KEGG pathways related to metabolism. "Drug metabolism cytochrome P450" and "Metabolism of xenobiotics by cytochrome P450" were among the five most deregulated signaling cascades (Fig. 1C). Unsupervised hierarchical clustering of the most significantly deregulated genes (35 up- and 35 downregulated genes) clearly showed that despite the interindividual variability, $\mathrm{PHH}$ samples segregated according to whether they had been incubated or not with EGF (Fig. 1D). NR113 (asterisk in Fig. 1D) that encodes CAR, the master regulator of $C Y P 2 B 6$ gene induction, was among the genes downregulated upon incubation with $\mathrm{EGF}(\mathrm{FC}=0.31, \mathrm{q}=0.009)$.

EGF Reduces the Expression of CAR and CAR-Target Genes. To determine the role of EGF in CAR expression and signaling in PHHs, cells were incubated with CITCO, a CAR agonist, or with $\mathrm{PB}$, an indirect CAR activator, for 24 hours (from day 2 to day 3 postseeding) in the presence or absence of $10 \mathrm{ng} / \mathrm{ml}$ EGF. CITCO was used at a low concentration that does not activate PXR (Maglich et al., 2003). To rule out an indirect effect due to long-term treatment, EGF was added before (day 0 ) or concomitantly (day 2) with the activators. RT-qPCR analysis confirmed that, compared with untreated cells (UT), EGF specifically and reproducibly decreased CAR mRNA level (Fig. 2A), in the presence or not of CITCO and PB, but had a minor effect on PXR mRNA expression (not shown). Next, as PB can activate both CAR and PXR (Lehmann et al., 1998; Moore et al., 2000), the expression of their prototypical target genes CYP2B6 (Sueyoshi et al., 1999) and CYP3A4 was monitored. In the absence of EGF, PB and CITCO incubation increased $C Y P 2 B 6$ and $C Y P 3 A 4$ mRNA level compared with UT cells. Conversely, incubation with EGF before or concomitantly with the CAR activators strongly and significantly reduced $C Y P 2 B 6$ upregulation by CITCO and PB (Fig. 2B) and of CYP3A4 by CITCO, and to a lesser extent by PB (Fig. 2C). Of note, $C Y P 2 B 6$ basal level (UT samples) was also significantly affected by the presence of EGF in the medium (Fig. 2B).

These findings suggest that EGF targets rapidly and more specifically CAR signaling in PHHs by modulating its expression and possibly its activity.

EGF Affects CYP2B6 Induction via CAR. To better understand EGF effect on CAR signaling, CAR expression was downregulated using specific small interfering RNAs (siCAR) and a nontargeting siRNA as a negative control (siCT). After siRNA transfection at day 


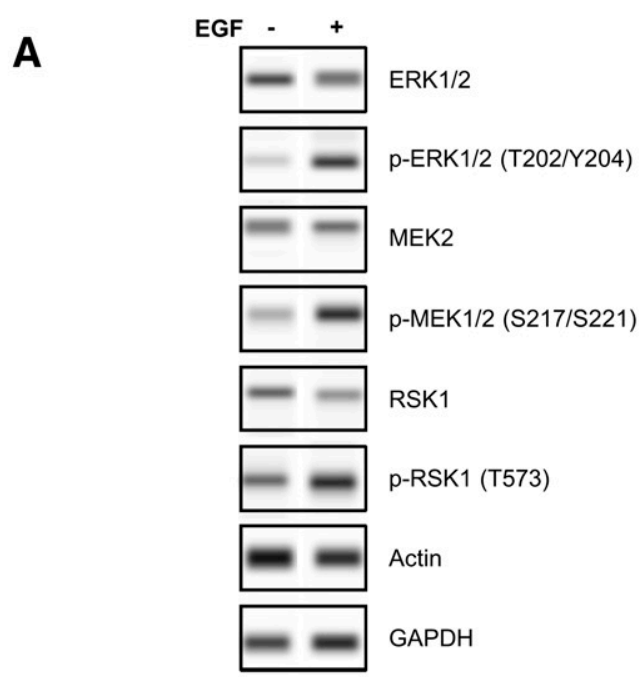

\section{B Enriched pathways for upregulated genes in EGF-treated PHHs}

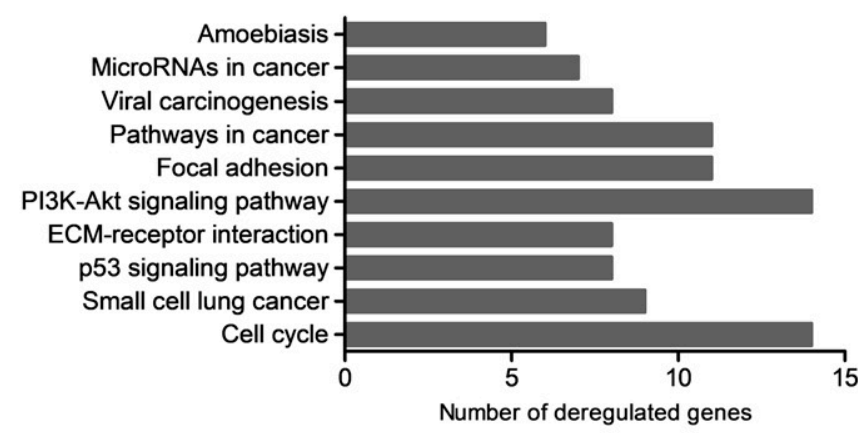

\section{Enriched pathways for downregulated genes in EGF-treated PHHs}

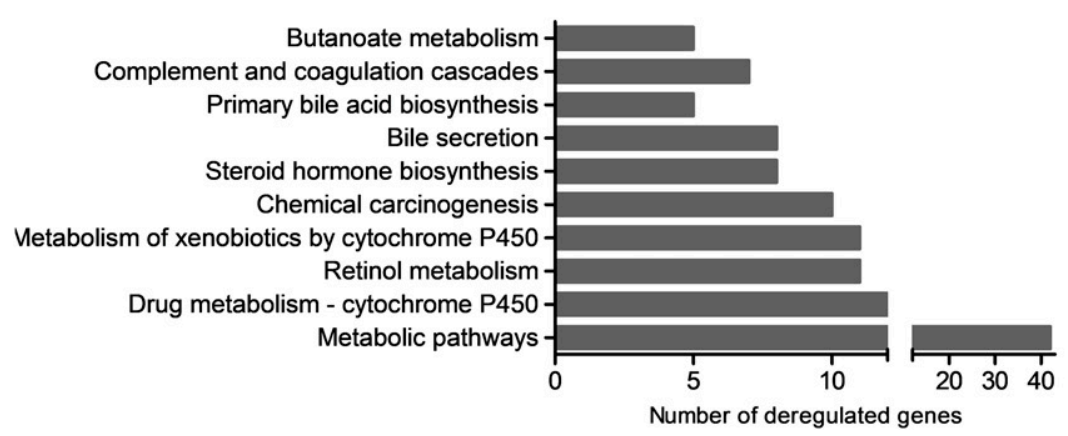

Fig. 1. Differential gene expression in PHHs following incubation with EGF. (A) DIGIWest analysis of protein expression in PHHs (Liv10, Table 1) following incubation or not with $10 \mathrm{ng} / \mathrm{ml} \mathrm{EGF}$ for 5 days. (B) Number of upregulated genes and enriched pathways in EGF-treated PHHs [false discovery rate $($ FDR $)=4.7 \times 10^{-18}-1.9 \times 10^{-5}$ ] (C) Number of downregulated genes and enriched pathways in EGF-treated PHHs (FDR $=8.8 \times 10^{-10}-0.008$ ). (D) Heat map showing the genes differentially expressed in PHHs $(n=5)$ following incubation with EGF.

2 and day 5, CAR mRNA expression was reduced by about 50\% independently of incubation with EGF (from day 1 to day 5) and CITCO or PB addition at day 5 for 24 hours (Fig. 3A). In parallel, CAR inhibition reduced $C Y P 2 B 6$ basal expression by twofold (Fig. 3B), as observed in the presence of EGF (Fig. 2B). In the absence of EGF, CYP2B6 mRNA was induced $\sim 15$ - and $\sim 17$-fold following CITCO and PB incubation, respectively, in siCT cells. This induction was reduced by more than 50\% in CAR-depleted PHHs (Fig. 3B, left). In the presence of EGF, CAR downregulation abolished CYP2B6 mRNA induction mediated by CITCO, whereas it did not significantly affect induction by PB (Fig. 3B, right), although EGF presence greatly affected $C Y P 2 B 6$ mRNA level. Western blot analysis of CYP2B6 expression confirmed these results (Fig. 3C). The different effects observed following incubation of PHHs with CITCO and PB and the impact of CAR downregulation suggest that EGF affects CYP2B6 induction via CAR.

EGF Differentially Affects the Response to CITCO and PB. Our previous observation was limited to $C Y P 2 B 6$, the prototypical CAR target gene. Therefore, EGF effect on CAR transcriptional activity in PHHs was assessed by transcriptomic analysis. First, to identify genes affected by EGF, the transcriptomic profiles of siCT-transfected PHHs incubated with CITCO or PB in the presence or absence of EGF were 

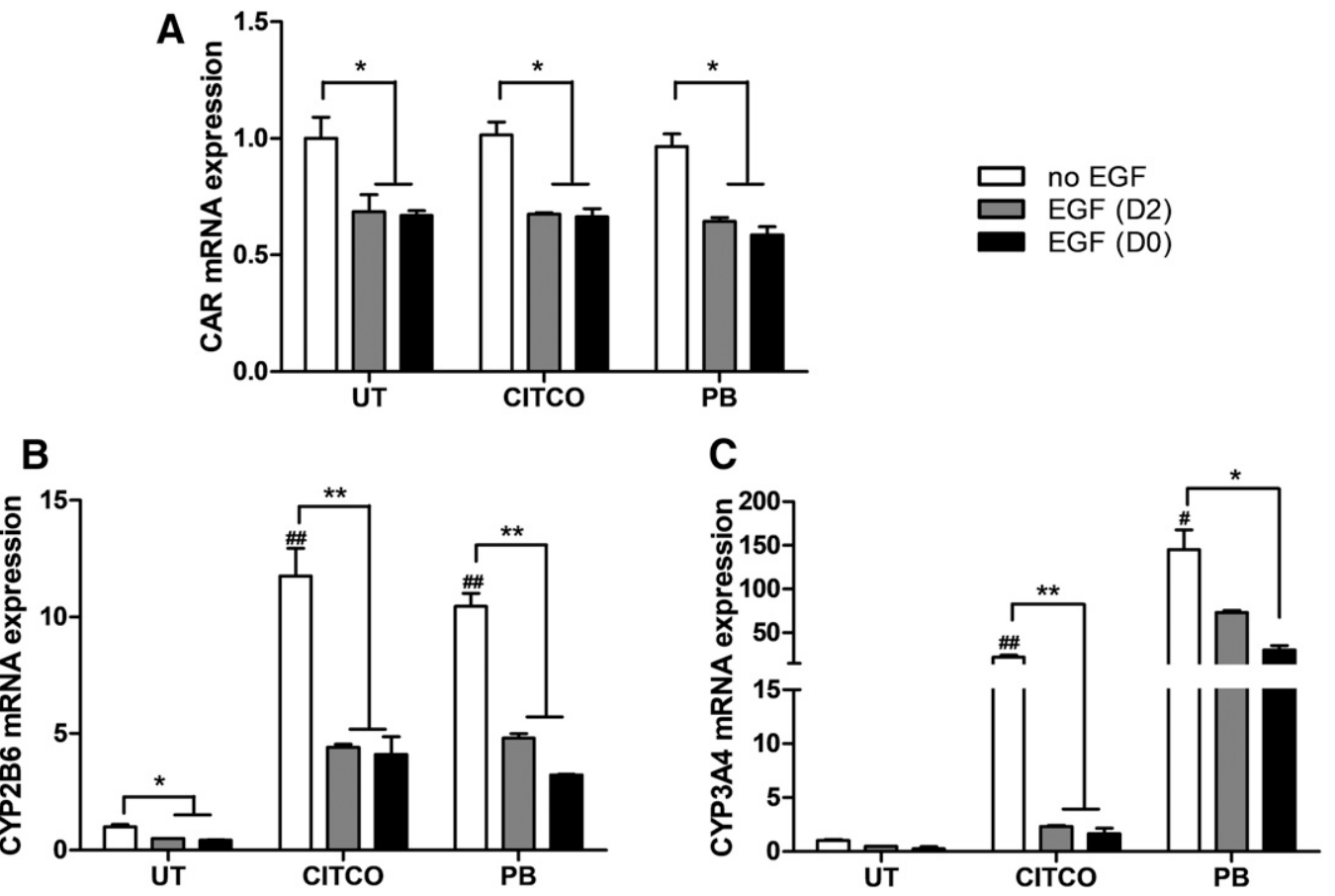

Fig. 2. EGF influences specifically the expression of CAR and its target genes in PHHs. PHHs from two donors (Liv1 and Liv2, Table 1) were incubated with $1 \mu \mathrm{M}$ CITCO, $0.5 \mathrm{mM} \mathrm{PB}$, or dimethylsulfoxide (DMSO) (UT) for 24 hours in the absence or presence of $10 \mathrm{ng} / \mathrm{ml}$ EGF. EGF was added before [day 0 (D0)] or together [day 2 (D2)] with the inducers. The relative expression of $C A R(\mathrm{~A}), C Y P 2 B 6(\mathrm{~B})$, and CYP3A4 (C) mRNA was measured by qPCR and normalized to RPLPO. Results are expressed relative to control (UT) in medium without EGF; ${ }^{*} P<0.05 ; * * P<0.01$, relative to control (no EGF) in the same treatment group; ${ }^{\#} P<0.05$; ${ }^{\# \#} P<0.01$, relative to control (UT).

analyzed (Fig. 4, A and B). Independently of EGF presence/absence, more genes were deregulated following incubation with $\mathrm{PB}$ than with CITCO (no EGF: 144 vs. 111; with EGF: 109 vs. 58, respectively), in
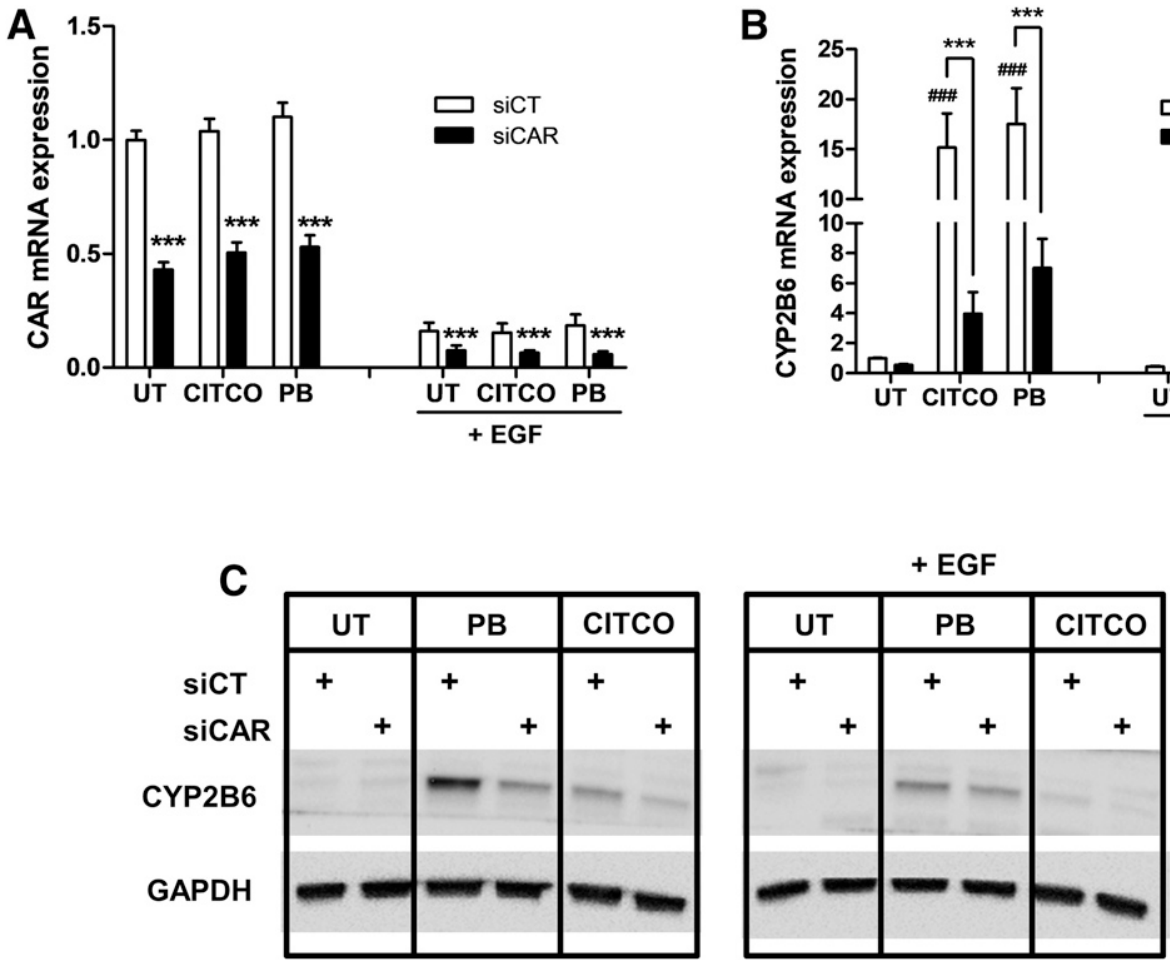

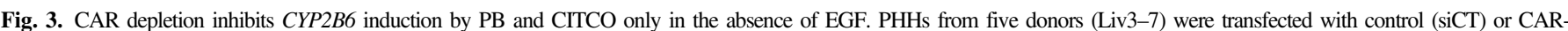

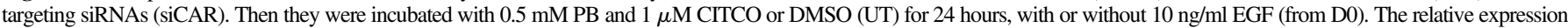

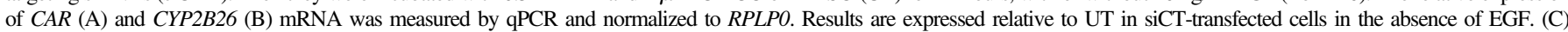

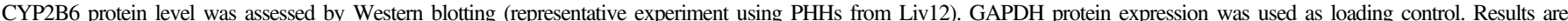

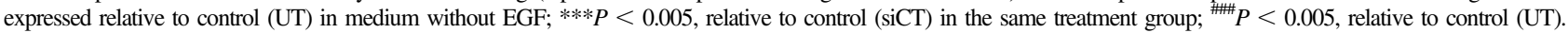




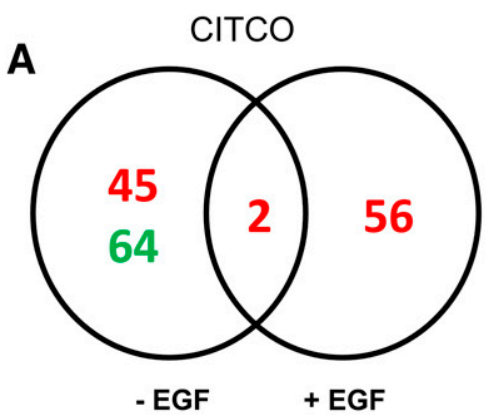

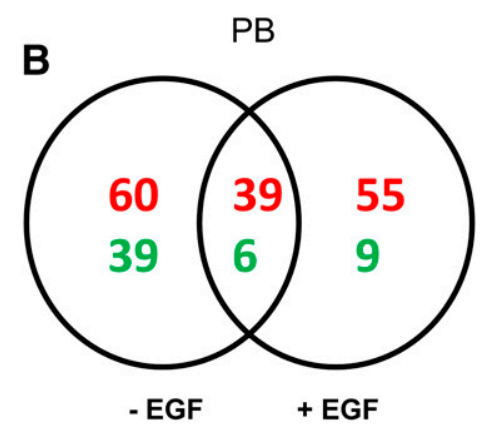

Fig. 4. EGF differentially affects the response to CITCO and PB. Venn diagrams showing the overlap of genes that are differentially expressed in PHHs from five donors (Liv3-7) upon incubation with $1 \mu \mathrm{M}$ CITCO (A) or $0.5 \mathrm{mM}$ PB (B) in the absence or presence of $10 \mathrm{ng} / \mathrm{ml}$ EGF (from D0). The number of up- and downregulated genes in each experimental condition is indicated in red and green, respectively. heterogeneous (up- and downregulation) in the absence of EGF. Further analysis revealed that only $C Y P 2 B 6$ and $C Y P 2 A 6$ (1.2\% of all deregulated genes after CITCO incubation) were significantly deregulated by CITCO in both the presence and absence of EGF (Fig. 4A). However, the FC values were different in the presence and absence of $\mathrm{EGF}(\mathrm{FC}=2.1 \mathrm{vs}$. 10.5 for $C Y P 2 B 6$, and $\mathrm{FC}=1.4$ vs. 14.8 for $C Y P 2 A 6$ ). On the other hand, upon $\mathrm{PB}$ incubation, 45 genes (21.6\% of all deregulated genes, including $C Y P 2 A 6$ and $C Y P 2 B 6$ ) were affected both in the absence and presence of EGF (Fig. 4B), with a weak effect of EGF on their FC (data not shown). Functional characterization demonstrated that most of the 109 genes deregulated by CITCO only in the absence of EGF encoded drug-metabolizing enzymes and were associated with xenobiotic metabolic processes (Table 3). A similar pattern was observed for the
45 PB-deregulated genes that do not depend on EGF (Table 4). Surprisingly, among the genes deregulated by PB (64 genes) or CITCO (56 genes) only in the presence of EGF, many were associated with mRNA processing. Moreover, in the absence of EGF, most of the deregulated genes in response to PB were associated with lipid and steroid metabolism.

Finally, comparison of the KEGG pathway enrichment for the genes deregulated in siCT-transfected PHHs incubated with PB (Fig. 5A) or CITCO (Fig. 5B) for 24 hours with or without EGF (relative to UT cells) showed that in the absence of EGF, most of the enriched pathways belonged to metabolism, whatever the treatment. This profile was weakly affected by EGF in cultures incubated with PB. In contrast, in the presence of EGF, CITCO-deregulated genes were no more associated with any enriched KEGG pathway.

TABLE 3

Enriched biologic processes after incubation of PHHs with CITCO

\begin{tabular}{clrc}
\hline GO Number & \multicolumn{1}{c}{ Biologic Process } & Count & $P$ Value \\
\hline Deregulated by & CITCO in the absence of EGF only & & \\
GO.0042738 & Exogenous drug catabolic process & 6 & $1.09 \mathrm{e}-05$ \\
GO.0016098 & Monoterpenoid metabolic process & 4 & $4.66 \mathrm{e}-05$ \\
GO.0019373 & Epoxygenase P450 pathway & 5 & 0.000103 \\
GO.0042221 & Response to chemical & 41 & 0.000103
\end{tabular}

GO.0050896

Response to stimulus

58

0.000166

GO.0097267

GO.0006805

Omega hydroxylase P450 pathway

Xenobiotic metabolic process

GO.0071466

GO.0070989

GO. 1901700
Cellular response to xenobiotic stimulus

Oxidative demethylation

Response to oxygen-containing compound

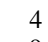

4
9

9

4

4
20

Deregulated by CITCO in the presence of EGF only

GO.0006397

GO.0048255

GO.0016071

mRNA processing

mRNA stabilization

mRNA metabolic process

GO.0008380
RNA splicing
0.000166

0.000299

0.00033

0.00102 0.00389
CYP1A2, CYP2A7, CYP2C19, CYP2C8, CYP2C9, CYP3A4

CYP1A2, CYP2C19, CYP2C9, CYP3A4

CYP1A2, CYP2A7, CYP2C19, CYP2C8, CYP2C9

ADCY2, AKR1B1, ANXA3, CA3, CPEB3, CREB3L3, CTGF,

CXCL5, CYP1A2, CYP2A7, CYP2C19, CYP2C8, CYP2C9, CYP3A4, CYP3A43, CYP3A7, EPHX1, ETV1, F2R, GSTA1, IL18, ITGA2, KCNA5, KRT19, MATN2, MICALL1, MRC1, MYL9, OR1C1, OR51B4, PANX1, PF4V1, POR, SERPINE1, SLC23A1, SOCS2, SOX2, TGFB2, TMEM67, TNFSF11, WNT6

ADCY2, AK7, AMOTL1, ANO1, BOC, CA3, CPE, CPEB3, CRIM1, CXCL5, CYP1A2, CYP2A7, CYP2C19, CYP2C8, CYP2C9, CYP3A4, CYP3A43, CYP3A7, DKK3, DST, EPHX1, ETV1, F2R, GSTA1, HRH4, IL18, ITGA2, KCNA5, KRT19, LRRN4, MAP4K5, MATN2, MCTP2, MICALL1, MRC1, MYL9, NABP1, OR1C1, OR51B4, PF4V1, PLK2, PNMA1, POR, RASEF, RRAD, RRM1, SERPINE1, SLC23A1, SOCS2, STK17A, SUSD4, TACSTD2, TGFB2, TMEM67, TNC, TNFSF11, VSIG4, WNT6

CYP1A2, CYP2C19, CYP2C8, CYP2C9

CYP1A2, CYP2A7, CYP2C19, CYP2C8, CYP2C9, CYP3A4, CYP3A43, CYP3A7, GSTA1

CYP1A2, CYP2A7, CYP2C19, CYP2C8, CYP2C9, CYP3A4, CYP3A43, CYP3A7, GSTA1

CYP1A2, CYP2C8, CYP2C9, CYP3A4

ADCY2, AKR1B1, CA3, CPEB3, CTGF, CXCL5, CYP1A2, F2R, IGFBP1, IL18, KCNA5, MRC1, PANX1, PAX2, PF4V1, POR, SERPINE1, SOCS2, TGFB2, WNT6

DHX9, HNRNPC, MBNL2, RBM22, RBM27, SON, SRRM2, SYNCRIP, THRAP3

DHX9, HNRNPC, SYNCRIP, THRAP3

DHX9, EIF4G1, HNRNPC, MBNL2, RBM22, RBM27, SON, SRRM2, SYNCRIP, THRAP3

DHX9, HNRNPC, MBNL2, RBM22, SON, SRRM2, SYNCRIP, THRAP3 
TABLE 4

Enriched biologic processes following incubation of PHHs with PB

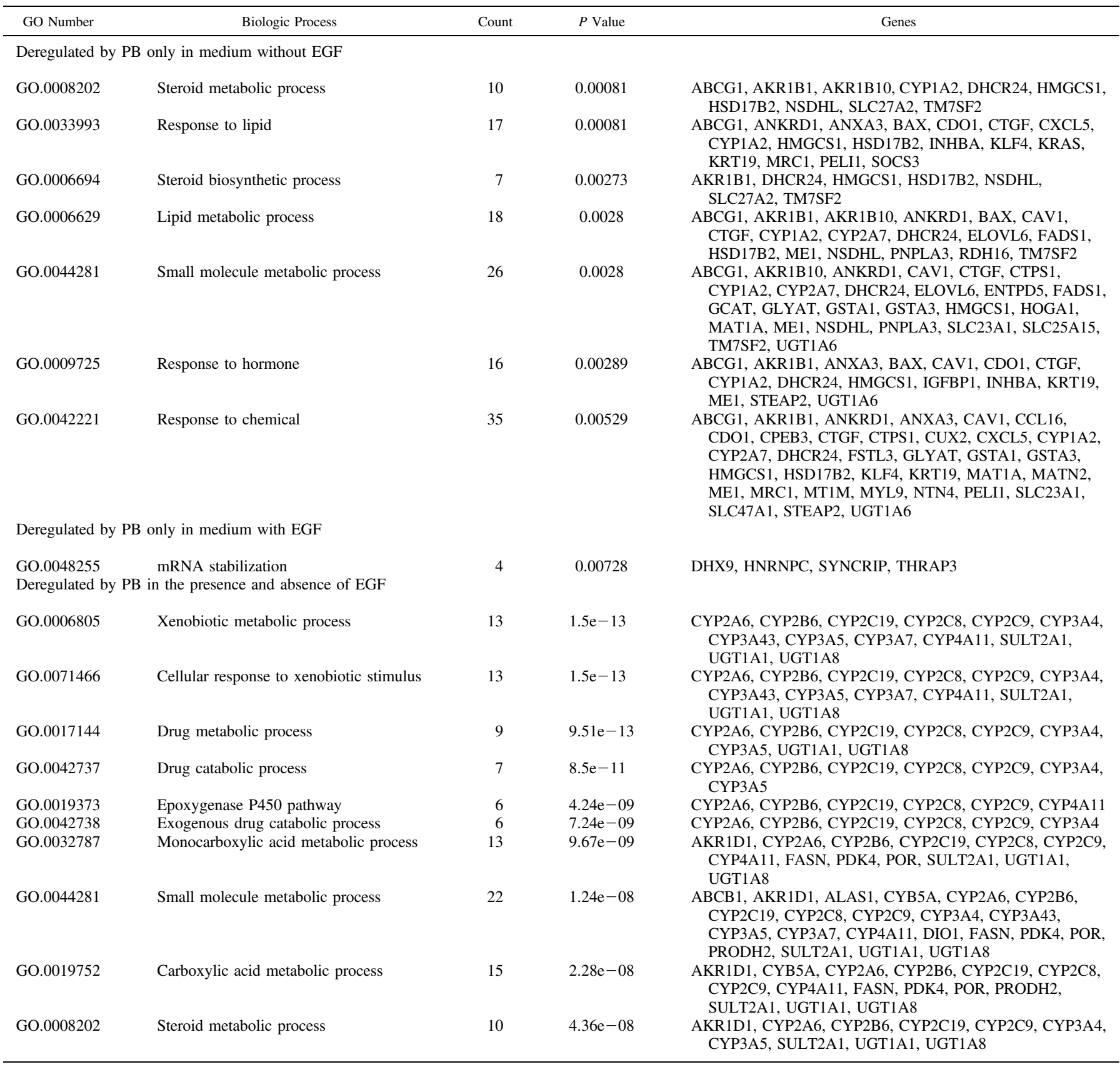

Identification of CAR Target Genes. The role of CAR in gene induction following incubation with CITCO or PB (with or without EGF) was then assessed in PHHs in which CAR was downregulated by siCAR transfection. On the basis of their unresponsiveness to CITCO or PB in siCAR cells compared with siCT cells, a list of CAR target genes was identified (Table 5). Among the 111 genes deregulated by CITCO in the absence of EGF in siCT cells (Fig. 4A), only 15 genes were identified as CAR-target genes. They included previously described CAR targets (CYP2B6, -2A6/7, -2C8/9, 3A4/7/43, EPHX1, ALAS1, and POR) and four new potential up (RDH16, TSKU, CPEB3)- and downregulated $(T A G L N)$ genes (Table 5). Among the 144 genes induced by PB in the absence of EGF in siCT cells (Fig. 4B), most $(n=140)$ were regulated in a CAR-independent manner. Among the few CAR targets in PB-treated
PHHs, $C Y P 2 B 6$ and $C Y P 2 A 6 / 7$ were also induced by CITCO, whereas STEAP2 was specifically downregulated by $P B$.

In the presence of EGF, among the 58 genes deregulated following CITCO treatment in siCT cells, only $C Y P 2 B 6$ and $C Y P 2 A 6$ were regulated by CITCO in a CAR-dependent manner. Conversely, upon incubation with $\mathrm{PB}$ in the presence of EGF, no gene was regulated in a CAR-dependent manner (Table 5).

These results were validated by qPCR analysis. In siCT cells, CYP2A6 and CYP2A7 (Fig. 6, A and B) were similarly induced by PB and $\mathrm{CITCO}$ in the absence of EGF. This induction was strongly reduced following CAR downregulation (siCAR). In the presence of EGF, induction of $C Y P 2 A 6$ and $C Y P 2 A 7$ by CITCO and PB was strongly reduced in siCT cells. CITCO-mediated induction was abolished 

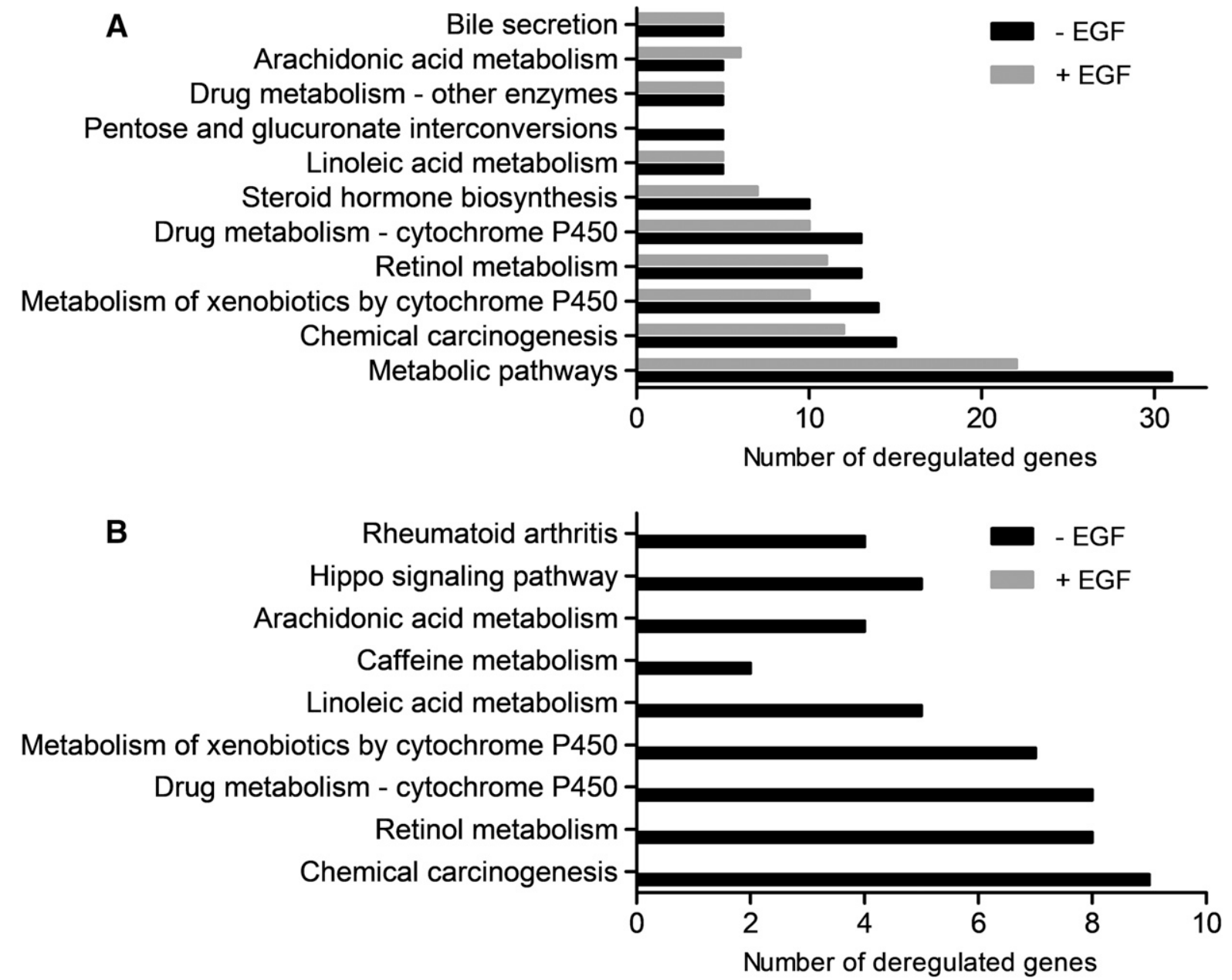

Fig. 5. KEGG pathway enrichment, relative to untreated cells, of siCT-transfected PHHs from five donors (Liv3-7) incubated with $0.5 \mathrm{mM}$ PB (A) or $1 \mu \mathrm{M}$ CITCO (B) for 24 hours in the presence or absence of $10 \mathrm{ng} / \mathrm{ml} \mathrm{EGF} \mathrm{(from} \mathrm{D0).}$

following CAR downregulation, whereas PB-mediated induction was less affected, as observed for $C Y P 2 B 6$ (Fig. 3B). In the absence of EGF, CYP3A4, CYP3A43, CYP3A7, CYP2C8, CYP2C9, TSKU, EPHX1, and POR (Fig. 6, C-J; Table 5) upregulation by CITCO depended on CAR expression, whereas most of the $\mathrm{PB}$-induced genes were $\mathrm{CAR}$ independent, but for $C Y P 2 C 8$ and TSKU. CAR contribution, monitored by the degree of siCAR-mediated inhibition of CITCO-induced response, varied among genes and was positively correlated with EGF inhibitory effect on gene expression. Addition of EGF did not change the FC induction of these genes by PB in controls (siCT) and CAR-depleted cells. Conversely, EGF abolished completely CITCO effect on the induction of these genes (Fig. 6, C-L), as shown for $C Y P 2 B 6$ (Fig. 3B). This pattern was not observed for $C P E B 3$ and STEAP2 (Fig. 6, M and $\mathrm{N})$. These results suggest that EGF deeply affects the drug metabolism response in PHHs.

Analysis of EGF effect on PHH transcriptome profile highlighted important differences compared with EGF-free cultures. As CAR expression is inhibited by EGF, no effect of CITCO was expected in the presence of EGF. Surprisingly, 58 genes were still upregulated upon incubation of PHHs with CITCO in the presence of EGF (Fig. 4A), and 55 of these genes were deregulated also by PB (Fig. 4B).

Altogether PHH transcriptomic analysis showed that 1) EGF strongly affects the transcriptional activity of the xenosensor CAR and 2) $\mathrm{PHH}$ response to $\mathrm{PB}$ is much less sensitive to EGF than that to CITCO, suggesting that CAR-independent mechanisms are involved.
In the Presence of EGF, PXR Regulates CAR Target Genes. It is well known that PXR shares ligand and target genes with CAR in humans (Moore et al., 2000). Recently, Kandel et al. (2016) demonstrated, using human hepatocytes, that CAR and PXR activation by CITCO and RIF, respectively, deregulate the same pathways (including the drug metabolism pathway). Our results showed that EGF negatively affects CAR expression and that a set of genes can still be induced by PB in the presence of EGF in siCAR cells. Therefore, we hypothesized that in the presence of EGF, PXR can take the place of CAR. To test this hypothesis, the effect of CITCO and PB, in the presence or absence of EGF, was assessed in PHHs after siRNA-mediated downregulation of PXR (siPXR). In PHHs transfected with siPXR, a 50\% reduction of PXR mRNA was observed, independently of the presence of PB, CITCO, or EGF (Fig. 7A). CAR mRNA level was not affected (Fig. 7B). Different from what observed in siCAR cells, in the absence of EGF, PB- and CITCO-mediated CYP2B6 induction was not inhibited upon PXR downregulation (Fig. 7C). Conversely, in the presence of EGF, PB-mediated CYP2B6 induction was significantly reduced by PXR downregulation, while CITCO-mediated induction was not affected. CYP3A4 mRNA was upregulated by CITCO only in the absence of EGF (Figs. 2B and 7D; Table 5), and its induction by PB depended on PXR, both in the presence or absence of EGF. These data suggest that in the presence of EGF, PB effect on $C Y P 2 B 6$ and $C Y P 3 A 4$ expression could be mediated via PXR rather than CAR. This was confirmed by siRNAmediated downregulation of both CAR and PXR (Fig. 7E). Indeed, in 
TABLE 5

List of genes differentially regulated by CITCO and PB in a CAR-dependent manner

\begin{tabular}{|c|c|c|c|c|c|c|c|c|c|c|c|c|c|c|c|c|}
\hline & \multicolumn{8}{|c|}{ siCT } & \multicolumn{8}{|c|}{ siCAR } \\
\hline & \multicolumn{4}{|c|}{$-\mathrm{EGF}$} & \multicolumn{4}{|c|}{$+\mathrm{EGF}$} & \multicolumn{4}{|c|}{$-\mathrm{EGF}$} & \multicolumn{4}{|c|}{$+\mathrm{EGF}$} \\
\hline & \multicolumn{2}{|c|}{ CITCO } & \multicolumn{2}{|c|}{ PB } & \multicolumn{2}{|c|}{ CITCO } & \multicolumn{2}{|c|}{ PB } & \multicolumn{2}{|c|}{ CITCO } & \multicolumn{2}{|c|}{ PB } & \multicolumn{2}{|c|}{ CITCO } & \multicolumn{2}{|c|}{$\mathrm{PB}$} \\
\hline & $\mathrm{FC}$ & $q$-value & $\mathrm{FC}$ & $q$-value & $\mathrm{FC}$ & $q$-value & $\mathrm{FC}$ & $q$-value & $\mathrm{FC}^{*}$ & $q$-value & $\mathrm{FC}^{* *}$ & $q$-value & $\mathrm{FC}^{*}$ & $q$-value & $\mathrm{FC}^{* *}$ & $q$-value \\
\hline TAGLN & 0.6 & 0.0 & 0.6 & 0.0 & 1.4 & 7.5 & 1.1 & N.S. & 1.4 & 0.0 & & N.S. & & N.S. & & N.S. \\
\hline RDH16 & 1.3 & 0.0 & 1.4 & 0,0 & 0.9 & N.S. & 1.1 & N.S. & 0.7 & 0.0 & & N.S. & & N.S. & & N.S. \\
\hline ALAS1 & 1.4 & 0.0 & 3.3 & 0.0 & 1.1 & N.S. & 2.3 & 0.0 & 0.7 & 0.0 & & N.S. & & N.S. & & N.S. \\
\hline POR & 1.5 & 0.0 & 2.6 & 0.0 & 1.1 & N.S. & 2.4 & 0.0 & 0.7 & 0.0 & & N.S. & & N.S. & & N.S. \\
\hline CYP2C9 & 1.5 & 0.0 & 1.8 & 0.0 & 1.1 & N.S. & 1.8 & 0.0 & 0.7 & 0.0 & & N.S. & 0.7 & 5.3 & & N.S. \\
\hline CPEB3 & 1.6 & 0.0 & 2.7 & 0.0 & 1.0 & N.S. & 1.3 & N.S. & 0.7 & 0.0 & & N.S. & & N.S. & & N.S. \\
\hline CYP2C8 & 1.7 & 0.0 & 2.3 & 0.0 & 1.1 & N.S. & 3.7 & 0.0 & 0.7 & 0.0 & & N.S. & & N.S. & & N.S. \\
\hline CYP3A43 & 1.9 & 0.0 & 5.4 & 0.0 & 1.0 & N.S. & 2.3 & 0.7 & 0.6 & 0.0 & & N.S. & & N.S. & & N.S. \\
\hline EPHX1 & 2.1 & 0.0 & 2.3 & 0.0 & 1.3 & N.S. & 1.7 & 0.4 & 0.6 & 0.0 & & N.S. & & N.S. & & N.S. \\
\hline TSKU & 2.4 & 0.0 & 3.8 & 0.0 & 1.2 & N.S. & 3.1 & 0.0 & 0.5 & 0.0 & & N.S. & & N.S. & & N.S. \\
\hline CYP3A7 & 2.4 & 0.0 & 6.0 & 0.0 & 0.9 & N.S. & 11.4 & 1.0 & 0.5 & 0.0 & & N.S. & & N.S. & & N.S. \\
\hline CYP2A7 & 3.5 & 0.0 & 3.6 & 0.0 & 1.1 & N.S. & 1.3 & N.S. & 0.5 & 0.0 & 0.6 & 0.0 & & N.S. & & N.S. \\
\hline CYP3A4 & 3.8 & 0.0 & 14.4 & 0.0 & 1.1 & N.S. & 23.8 & 0.0 & 0.4 & 0.0 & & N.S. & & N.S. & & N.S. \\
\hline CYP2B6 & 10.5 & 0.0 & 10.7 & 0.0 & 2.1 & 1.3 & 5.6 & 0.0 & 0.3 & 0.0 & 0.5 & 0.0 & 0.7 & 5.3 & & N.S. \\
\hline CYP2A6 & 14.8 & 0.0 & 15.4 & 0.0 & 1.4 & 0.7 & 1.9 & 0.0 & 0.2 & 0.0 & 0.3 & 0.0 & 0.7 & 5.3 & & N.S. \\
\hline STEAP2 & 0.8 & N.S. & 0.6 & 0.0 & 0.9 & N.S. & 0.8 & N.S. & & N.S. & 1.4 & 2.4 & & N.S. & & N.S. \\
\hline
\end{tabular}

FC, fold change (siCT-CITCO/siCT-DMSO or siCT-PB/siCT-DMSO); N.S., not significant; siCT, control siRNA; siCAR, anti-CAR siRNA. *siCAR-CITCO/siCT-CITCO;

**siCAR-PB/siCT-PB.

the presence of EGF, induction of $C Y P 2 B 6,-3 A 4,-2 C 8,-2 A 6,-2 A 7$, $-3 A 43$, and $T S K U$ by PB (Fig. 7F) was strongly reduced when PXR (but not CAR) expression was downregulated. Moreover, this effect was increased in cells in which both CAR and PXR were silenced, particularly for $C Y P 2 A 6$ and $C Y P 2 A 7$.

Finally, individual analysis of the effect of CITCO or PB (in the absence of EGF) in the different PHH cultures used for gene expression analysis $(n=8)$ indicated that CITCO-mediated induction of CYP2B6 mRNA expression was variable among samples (Fig. 8A). Moreover, it was significantly lower than the effect mediated by PB in Liv13 and Liv15, and almost no induction could be observed in Liv14 relative to UT cultures. Similarly, the relative CAR mRNA level in the different cultures was more heterogeneous than that of PXR (from 1 to 100 vs. 1 to 10, respectively, not shown). Comparison of CITCO effect and of the PXR/CAR mRNA expression ratio in the eight samples showed that in the absence of EGF, when the PXR/CAR mRNA ratio was low (Fig. 8B) (i.e., high CAR mRNA expression), CITCO-mediated CYP2B6 induction was high (Fig. 8A). Conversely, when the PXR/CAR mRNA ratio was high (i.e., low CAR mRNA expression), CITCO-mediated $C Y P 2 B 6$ induction was low. In the presence of EGF that downregulates CAR expression, CYP2B6 induction was lower after incubation with CITCO than with PB (Fig. 8C), and the PXR/CAR mRNA ratio values were higher (low CAR expression) (Fig. 8D). Moreover, siRNAmediated CAR or PXR downregulation in two samples that poorly responded to CITCO (Liv13 and Liv15) showed that CYP2B6 upregulation by PB depended on PXR activity (Fig. 8, E and F), both in the presence and absence of EGF.

In conclusion, a switch from CAR to PXR dependency in PB-target gene induction is observed when CAR expression is low and in the presence of EGF. This observation could be critical for the development of target therapies.

\section{Discussion}

Growth factors play crucial roles in liver physiology, and the involvement of some of them in CAR activity and expression has been widely studied. However, few data are available on EGF role in PHHs.
Here, by using a direct and an indirect CAR activator, we show that EGF influences the expression of $C A R$ and $C Y P 2 B 6$, the prototypical CAR target gene, in PHHs. We then found that few genes are strictly CAR dependent in PHHs. Moreover, in this cell model, the indirect CAR activator PB modulates gene expression differentially in the absence or presence of EGF, but mostly in a CAR-independent and PXR-dependent manner. This may influence the design and interpretation of drug investigation studies.

Very few studies have analyzed PHH transcriptome profile following activation of human CAR in vitro. Kandel et al. (2016) performed a genome-wide comparison of the inducible transcriptomes of the nuclear receptors CAR, PXR and PPAR $\alpha$ in PHHs (Kandel et al., 2016). Li et al. (2015) studied genome-wide the transcriptome profiles of parental and HepaRG cells where NR1I3 was knocked down (CAR-KO). Surprisingly, we identified only 15 CAR target genes among the 111 genes differentially regulated by CITCO and only four among the 144 genes affected by PB. Conversely, Li et al. (2015) found that in HepaRG cells, the expression of 135 genes and of more than 120 genes was affected by CITCO and by PB, respectively, in a CAR-dependent manner ( $\mathrm{Li}$ et al., 2015). The difference in the number of deregulated genes could be linked to the cell type (HepaRG cells vs. PHHs). Moreover, CAR silencing by siRNA led to a decrease of only approximately $50 \%$ of $C A R$ mRNA expression in PHHs. Therefore, we cannot rule out that the remaining CAR protein is enough to regulate gene expression and that we only identified the major CAR targets. However, the observation that CYP2B6 expression was significantly downregulated in CAR-depleted hepatocytes after treatment with CITCO suggests that the silencing strategy was effective. In addition, $\mathrm{PB}$ and CITCO off-target effects have been already reported (Ueda et al., 2002; Li et al., 2015). Therefore, our results are in agreement with $\mathrm{PB}$ nonspecific and pleiotropic effects and its possible cross-activation of PXR and also highlight the poorly described CAR-independent CITCO activity.

Most of the identified CAR target genes have been previously described (ALAS1, POR, CYP2A6 -2A7 -2B6 $-2 C 8$-2C9 $-3 A 4$-3A7, $E P H X 1)$ (Kandel et al., 2016) and we found only four new genes, of which three were validated by PCR (TSKU, TAGLN, RDH16). $C Y P 2 B 6, C Y P 2 A 6$, and $C Y P 2 A 7$ were the only genes modulated in a 
A

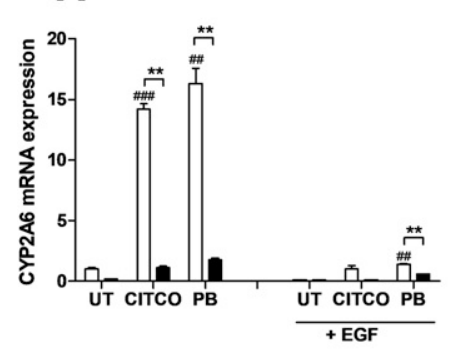

C

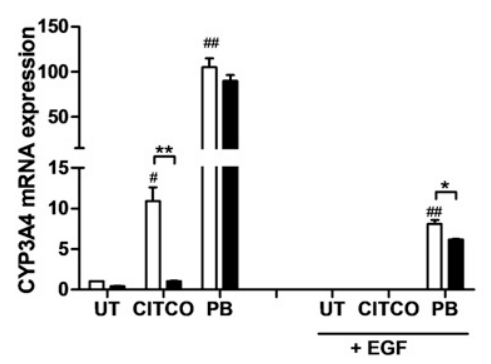

F

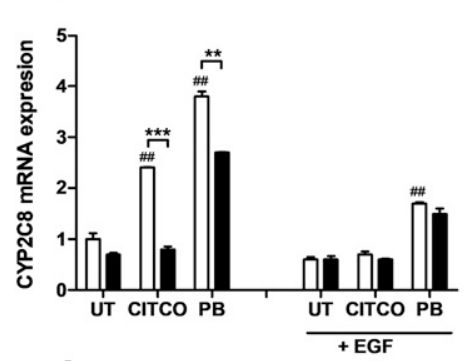

I

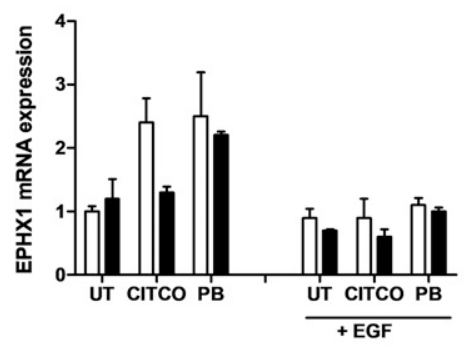

L

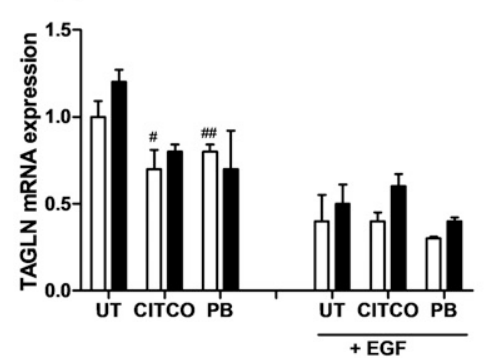

B

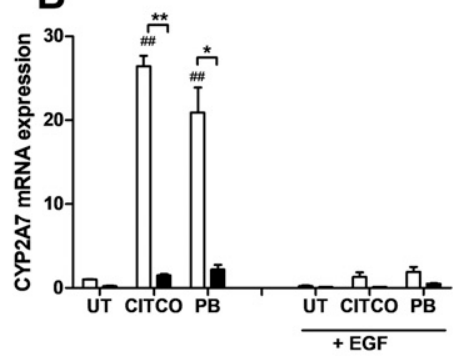

D

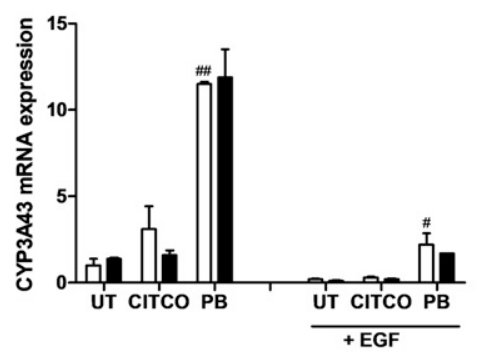

G
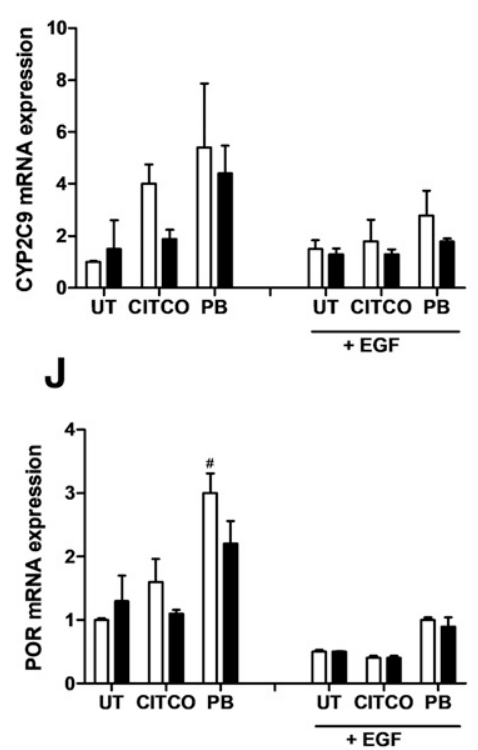

M

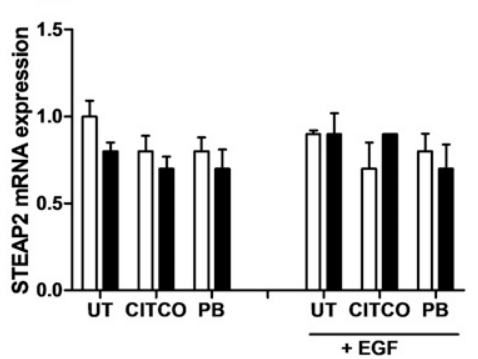

E

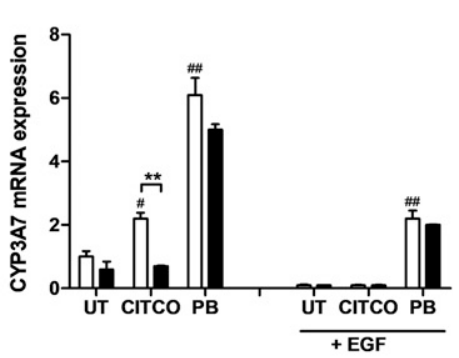

H

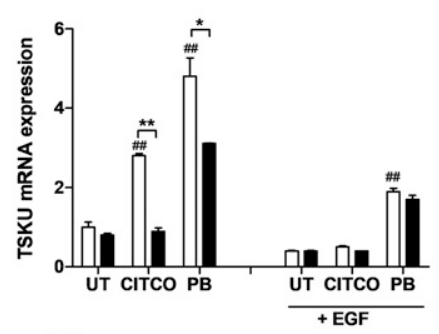

K

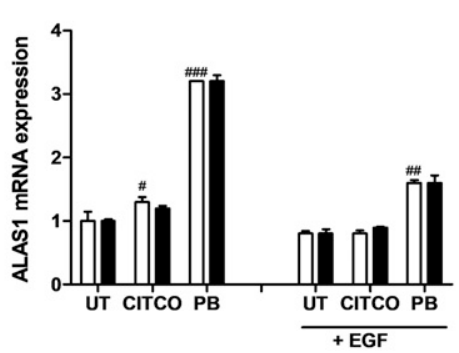

N

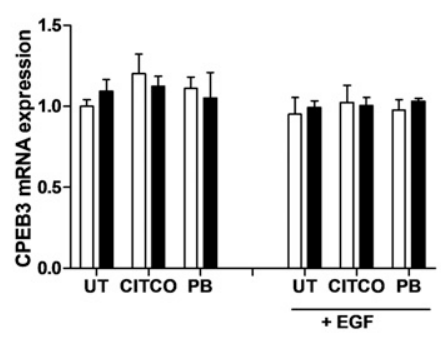

Fig. 6. PHHs from two donors (Liv6 and Liv7, Table 1) were transfected with control (siCT) or CAR-targeting siRNAs (siCAR). They were then incubated with 0.5 mM $\mathrm{PB}, 1 \mu \mathrm{M}$ CITCO, or DMSO (UT) for 24 hours, in the presence or not of $10 \mathrm{ng} / \mathrm{ml}$ EGF (from D0). The relative expression of CYP2A6 (A), CYP2A7 (B), CYP3A4 (C), CYP3A43 (D), CYP3A7 (E), CYP2C8 (F), CYP2C9 (G), TSKU (H), EPHX1 (I), POR (J), ALAS1 (K), TAGLN (L), STEAP2 (M), and CEBP3 (N) mRNA was measured by qPCR and normalized to RPLPO. Results are expressed relative to not treated siCT-transfected PHHs (UT) in medium without EGF. $* P<0.05 ; * * P<0.01$, relative to control in the same treatment group; ${ }^{\#} P<0.01$; ${ }^{\# \#} P<0.005$, relative to control (UT).

CAR-dependent manner by both PB and CITCO. $C Y P 2 A 6$ and $C Y P 2 A 7$ are located in close proximity of $C Y P 2 B 6$ on chromosome $19 \mathrm{q} 13.2$, and common modulation mechanisms could be involved. Accordingly, several studies found that CYP2A6 (Maglich et al., 2003; Itoh et al.,
2006) and $C Y P 2 A 7$ (Kandel et al., 2016) are induced by CITCO in PHHs. TSKU is induced by PB in HepaRG cells and PHHs (Lambert et al., 2009) and is regulated by PXR in osteoblasts (Ichikawa et al., 2006).TAGLN, one of the new genes identified as downregulated by 
A

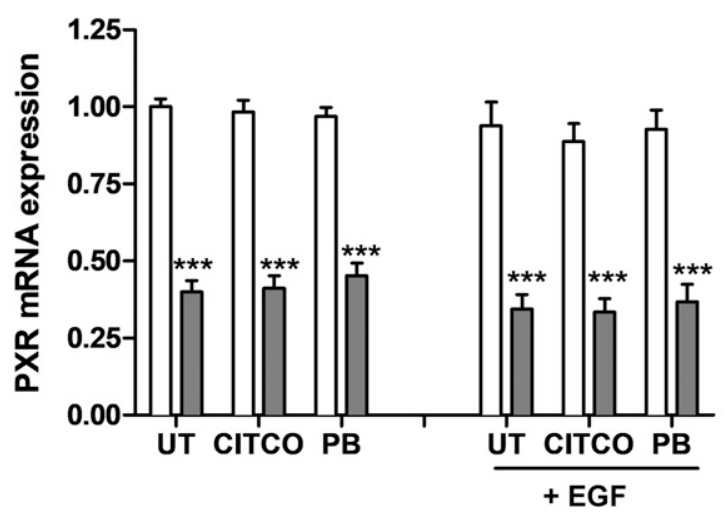

C

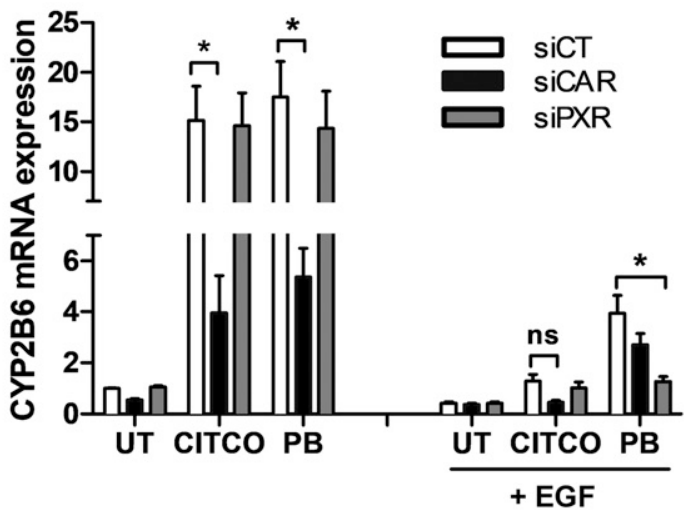

E

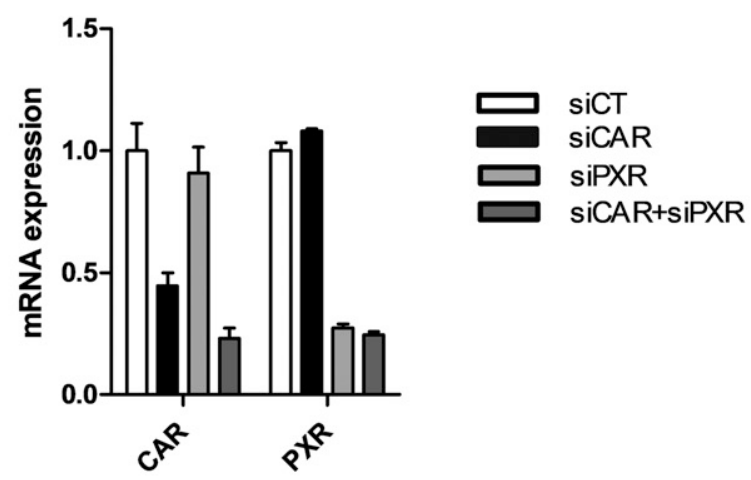

B
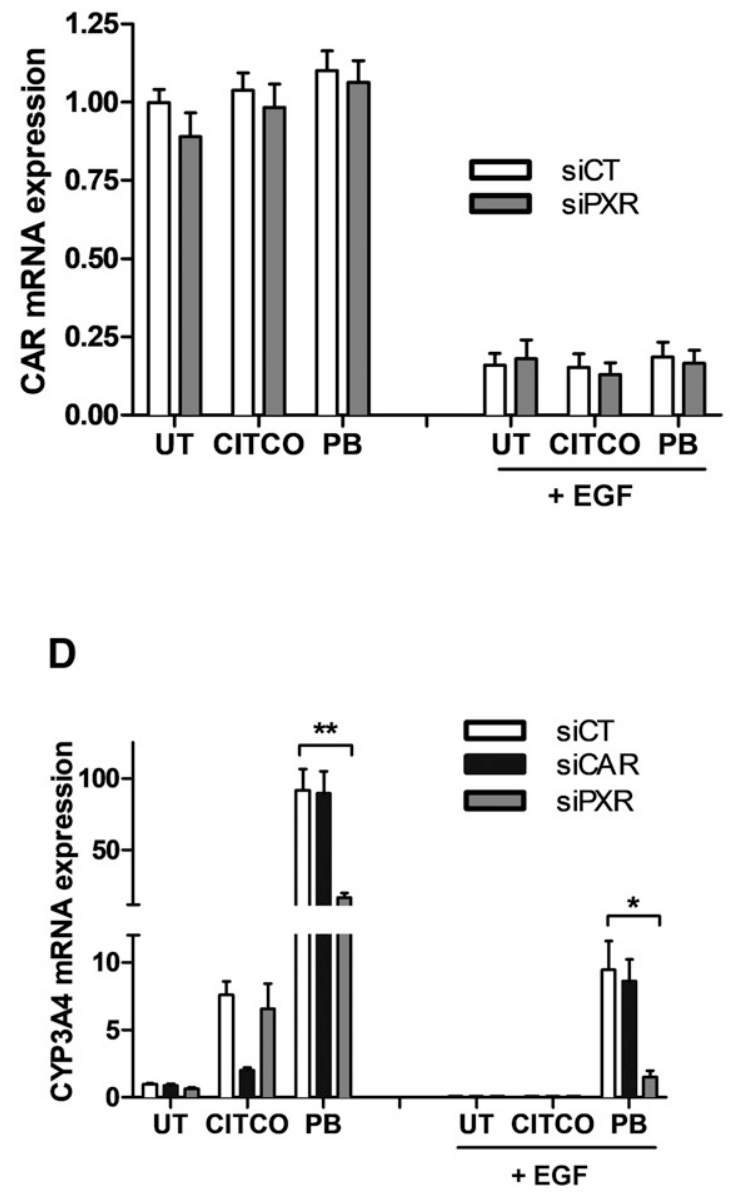

$\mathbf{F}$

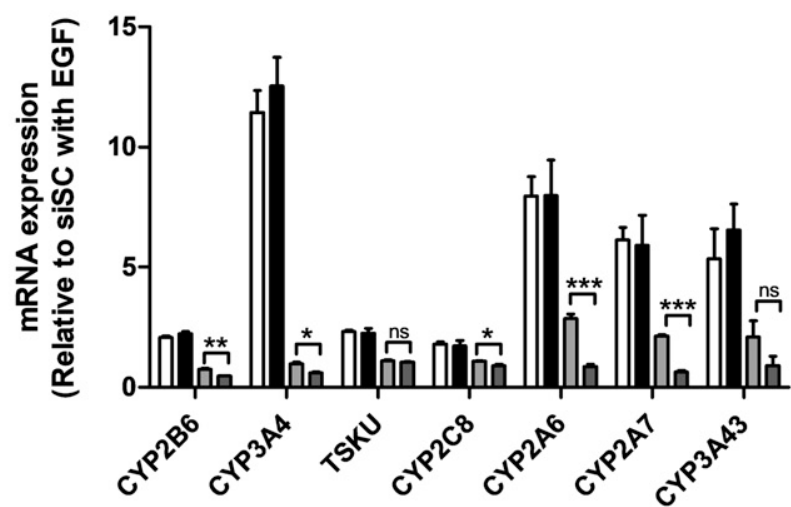

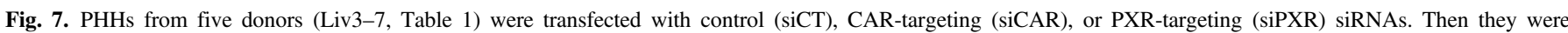

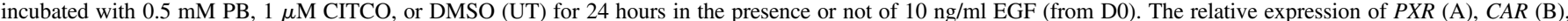

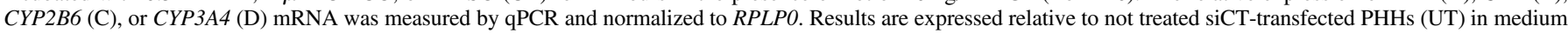

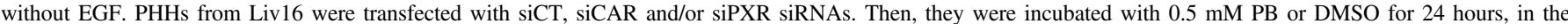

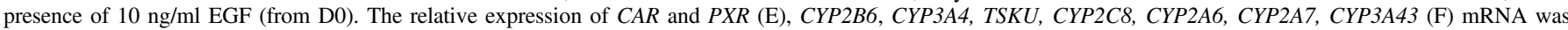

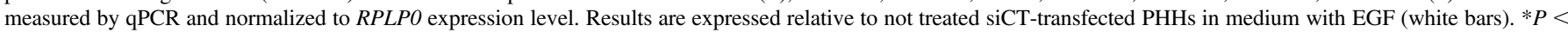
$0.05 ; * * P<0.01$; *** $P<0.001$ relative to control in the same treatment group.

CAR in the present study, encodes transgelin that is mainly expressed in stellate cells and fibroblasts (Petkov et al., 2004). We cannot rule out that PHHs may be contaminated by nonparenchymal cells. Retinol dehydrogenase 16 (RDH16) is involved in retinol synthesis. Its expression increases following PPAR $\alpha$ activation in PHHs (Kandel et al., 2016). In silico analysis revealed the presence of putative DR3 and DR4 motifs on its regulatory region, suggesting a possible regulation by CAR (Ebert et al., 2016). Our results demonstrate that in PHHs, only very few genes are strictly CAR dependent, suggesting that complementary mechanisms can promote the expression of xenobiotic-related genes. This 

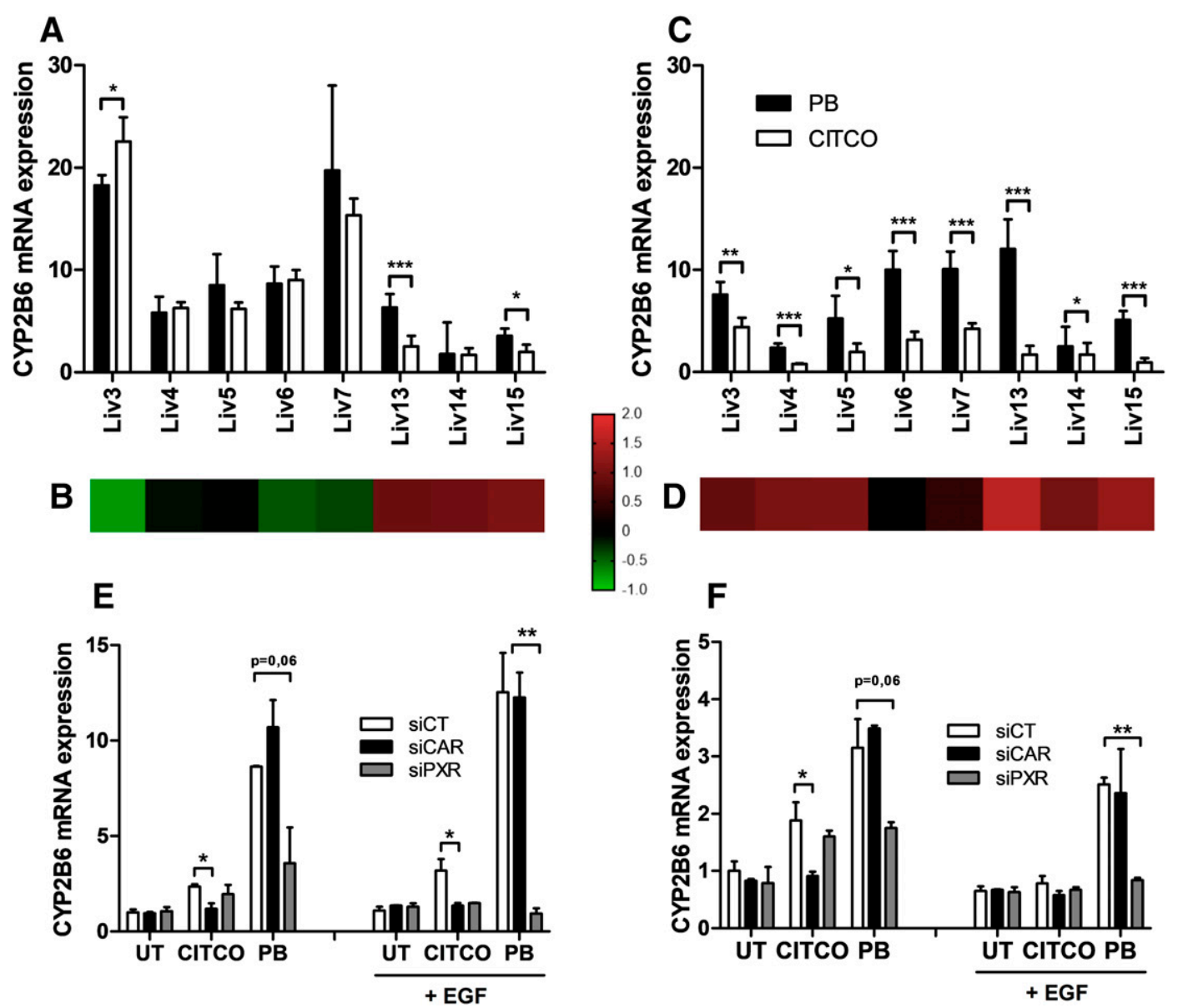

Fig. 8. PHHs from eight donors (Liv3-7 and 13-15, Table 1) were incubated with $0.5 \mathrm{mM} \mathrm{PB}, 1 \mu \mathrm{M}$ CITCO, or DMSO (UT) for 24 hours in the presence or not of $10 \mathrm{ng} / \mathrm{ml}$ EGF (from D0). The relative expression of CYP2B6 was measured by qPCR and normalized to RPLPO in the absence (A) or presence (C) of EGF. PXR/CAR mRNA expression ratio in the absence (B) or presence (D) of EGF (expressed as LOG10). PHHs from two donors (Liv13 and Liv15, Table 1) (E and F) were transfected with control (siCT), CAR-targeting (siCAR), or PXR-targeting (siPXR) siRNAs. They were then incubated with $0.5 \mathrm{mM} \mathrm{PB}, 1 \mu \mathrm{M}$ CITCO, or DMSO (UT) for 24 hours in the presence or not of $10 \mathrm{ng} / \mathrm{ml}$ EGF (from D0). The relative expression of CYP2B6 was measured by qPCR and normalized to RPLPO in the absence or presence of EGF. Results are expressed relative to not treated siCT-transfected PHHs (UT) in medium without EGF. $* P<0.05 ; * * P<0.01 ; * * *<0.001$.

could explain in part the difference between humans and mice. Studying CAR transcriptional regulation in rodents, using in vivo and in vitro approaches could help understanding whether our findings are specific to PHHs, or biased by the 2D culture model. Indeed, gene expression (Lauschke et al., 2016b) and energy metabolism (Fu et al., 2013) patterns rapidly change when human/rodent hepatocytes are seeded in culture. Therefore, although PHHs are the most relevant cell model for human studies, data obtained in vitro using this system should be interpreted with caution. During the last decade, cell culture strategies to mimic in vivo situations have been developed. Specifically hepatocytes have been cultured in 3D spheroids (Bachmann et al., 2015; Bell et al., 2016; Vorrink et al., 2017) in the presence or not of stromal cells (Khetani and Bhatia, 2008) and in association or not with medium flux (Vinci et al., 2011; Lin et al., 2015; Lauschke et al., 2016a). These conditions favor the long-term maintenance of cell viability and an in vivo-like hepatic phenotype, as indicated by transcriptomic, proteomic, and metabolomic analyses. This is accompanied by stable expression of phase I and phase II enzymes, phase III transporters, xenoreceptors (CAR and PXR), and transcription factors (HNF4), as well as improved cell-to-cell contacts and bile canalicular structure and activity compared with $2 \mathrm{D}$ culture conditions. Therefore, moving from monolayer to 3D cell culture systems can greatly improve nuclear receptor expression and genemediated regulation (Vorrink et al., 2017) as well as the in vitro assessment of drug metabolism and toxicity (Lin and Khetani, 2016).
It has been shown that in the liver of EGF2B transgenic mice, the expression of genes predisposing to malignancy is increased, whereas that of enzymes associated with retinoic acid and xenobiotic metabolism is downregulated (Borlak et al., 2005). Interestingly, we obtained similar results in PHHs. KEGG pathway analysis showed that in the presence of EGF, upregulated genes mostly belonged to the cell cycle and carcinogenesis pathways (Komposch and Sibilia, 2015). In addition, in the presence of EGF, pathways associated with drug metabolism-cytochrome P450 were downregulated (Fig. 1C). These pathways are downregulated also in CAR-KO HepaRG cells (Li et al. 2015), suggesting that the EGFmediated phenotype could be explained, at least in part, by CAR signaling deregulation (Li et al., 2015). This hypothesis is reinforced by the finding that the same KEGG pathways are upregulated in PHHs incubated with CITCO [this study and Kandel et al. (2016)]. This CITCO-mediated effect was almost completely abrogated by the presence of EGF (Fig. 5B).

In our model, we observed that EGF affects similarly CYP2B6 induction by CITCO and PB in short-term culture (day 2) (Fig. 2). In addition, after 6 days of culture in the presence of EGF, CITCOmediated $C Y P 2 B 6$ induction was lost, in contrast to the induction mediated by PB (Fig. 3). Our transcriptome analysis clearly revealed the strong EGF effect on CAR signaling when using CITCO as activator. In contrast, $\mathrm{PB}$ response was almost not affected by the presence of EGF. This is in agreement with PB nonspecific action, but also suggests a secondary compensatory mechanism. 
CAR activity regulation involves multiple mechanisms, including the AMPK, insulin, EGFR, and MEK-ERK signaling pathways (Yang and Wang, 2014; Yasujima et al., 2016). Conversely, CAR transcriptional regulation has been poorly studied. The hepatotrophic factor augmenter of liver regeneration reduces P450 enzyme activities in human hepatocytes partially through nuclear factor $\kappa \mathrm{B}$ activation and CAR downregulation (Dayoub et al., 2006). In a mouse model in which mouse HGF is overexpressed, CAR but not PXR mRNA expression is reduced (Kakizaki et al., 2007). It would be important to assess whether other growth factors and/or serum have a similar inhibitory effect in PHHs and in HepaRG cells (Aninat et al., 2006). In addition, EGF and serum downregulate CAR, but not PXR and retinoic $\mathrm{X}$ receptor expression in HepG2 cells (Osabe et al., 2009) via the SAPK signaling pathway. This may also occur in PHHs.

HNF- $4 \alpha$, PGC- $1 \alpha$, and glucocorticoid receptor are considered to be the main regulators of CAR promoter activity (Pascussi et al., 2003; Ding et al., 2006). Insulin-like growth factor-1 receptor inhibitor (Li et al., 2012) and thyroid hormone (Ooe et al., 2009) also modulate CAR expression. In addition, post-transcriptional regulation by miR-34-a (Lamba et al., 2014) and miR-137 (Chen et al., 2014) leads to NR113 downregulation. $\mathrm{HNF} 4 \alpha$ regulates both CAR transcriptional activity (Gonzalez, 2008) and expression (Ding et al., 2006; Kamiyama et al., 2007). However, HNF4 $\alpha$ gene expression was not affected by EGF in our model. Direct HNF4 $\alpha$ phosphorylation is another possible mechanism that could contribute to EGF effect in hepatocytes (De Boussac et al., 2010; Vetö et al., 2017).

Importantly, we found that in the presence of EGF, CAR does not modulate anymore the expression of its target genes (but for $C Y P 2 B 6$ and $C Y P 2 A 6$, to a lower extent). Using a gene silencing strategy, we could show that $\mathrm{PB}$ preferentially induces $C Y P 2 B 6$ by selective CAR activation, but can switch to PXR activation when CAR is present in limited amount (in the presence of EGF and when CAR is artificially downregulated). The finding that many genes modulated by PB independently of CAR in the presence of EGF are known PXR target genes (e.g., CYP2B6, CYP3A7, CYP2C8, CYP3A4, EPHX1, CYP3A43, $C Y P 2 C$ 9, THRSP, ALAS1, ABCC2, POR, CYP3A5, and $A B C B 1$ ) further supports the existence of a PXR-mediated compensatory mechanism that might allow overcoming the lack of response to potential threats. This conclusion is consistent with the enhanced role of human PXR in the absence of CAR competition observed in CAR-KO HepaRG cells (Li et al., 2015) and also with the asymmetric regulation of CYP3A4 and CYP2B6 by CAR or PXR previously reported by Faucette et al. (2006). We also observed that induction of drug metabolism enzymes depends on the PXR/CAR ratio. Similarly, a previous report using reporter genes in the mouse showed a crucial role of the PXR/CAR ratio in Cyp $2 b 10$ modulation (Ding and Staudinger, 2005). Considering the interindividual variability of CAR and PXR expression, this observation could have a critical impact in drug development.

Altogether, our findings bring new insights into EGF effect on CAR activity in PHHs that might be physiologically relevant and highlight the importance of transcriptional regulation in CAR biology. CAR transcriptional regulation may play an underestimated role in drug metabolism and transport, energy homeostasis, and cell proliferation. Furthermore, unlike the results described in rodents, our work shows that the indirect CAR activator PB modulates gene expression predominantly in a CAR-independent manner, although EGF significantly affects $\mathrm{PHH}$ response to this drug. It would be interesting to evaluate this effect using the most recent microfluidic and 3D spheroid culture systems in which nuclear receptor expression is maintained (Lauschke et al., 2016a; Vorrink et al., 2017). Finally, the switch between CAR and PXR for gene modulation in CAR-depleted cells highlights the crosstalk between these xenosensors in the presence of EGF. This crosstalk provides a mechanism for amplifying the body detoxification response to a broad range of chemicals.

In addition to their primary role in drug metabolism, CAR and PXR are also potential pharmacological targets for the treatment of cancers (De Mattia et al., 2016) and metabolic diseases, such as cholestasis, nonalcoholic fatty liver disease, and diabetes (Kakizaki et al., 2007; Gao and Xie, 2012). As PXR and CAR may differentially affect metabolic pathways, it is important to selectively target these receptors. In this context, controlling the microenvironment and culture conditions of the hepatic cells used for investigating CAR activity is crucial.

\section{Acknowledgments}

We thank A. Kassambara for bioinformatics advice and E. Vidal and F. Carol for technical support. This work benefitted from the equipment of the transcriptome facility of the University Hospital Centre (CHU) of Montpellier and from the expertise of Véronique Pantesco (v-pantesco@chumontpellier.fr), scientific manager of the facility.

\section{Authorship Contributions}

Conducted experiments: de Bousssac, Gondeau, Briolotti, Duret, Treindl, Römer, Templin, Gerbal-Chaloin.

Contributed new reagent and analytic tools: Fabre, Herrero, Ramos, Maurel. Performed data analysis: de Bousssac, Gerbal-Chaloin, Daujat-Chavanieu.

Wrote or contributed to the writing of the manuscript: de Bousssac, GerbalChaloin, Daujat-Chavanieu.

\section{References}

Aninat C, Piton A, Glaise D, Le Charpentier T, Langouët S, Morel F, Guguen-Guillouzo C, and Guillouzo A (2006) Expression of cytochromes P450, conjugating enzymes and nuclear receptors in human hepatoma HepaRG cells. Drug Metab Dispos 34:75-83.

Bachleda P, Vrzal R, and Dvorák Z (2009) Activation of MAPKs influences the expression of drug-metabolizing enzymes in primary human hepatocytes. Gen Physiol Biophys 28:316-320.

Bachmann A, Moll M, Gottwald E, Nies C, Zantl R, Wagner H, Burkhardt B, Sánchez JJ, Ladurner R, Thasler W, et al. (2015) 3D cultivation techniques for primary human hepatocytes. Microarrays (Basel) 4:64-83.

Bell CC, Hendriks DF, Moro SM, Ellis E, Walsh J, Renblom A, Fredriksson Puigvert L, Dankers AC, Jacobs F, Snoeys J, et al. (2016) Characterization of primary human hepatocyte spheroids as a model system for drug-induced liver injury, liver function and disease. Sci Rep 6:25187.

Berasain C and Avila MA (2014) The EGFR signalling system in the liver: from hepatoprotection to hepatocarcinogenesis. J Gastroenterol 49:9-23.

Borlak J, Meier T, Halter R, Spanel R, and Spanel-Borowski K (2005) Epidermal growth factorinduced hepatocellular carcinoma: gene expression profiles in precursor lesions, early stage and solitary tumours. Oncogene 24:1809-1819.

Chen S, He N, Yu J, Li L, Hu Y, Deng R, Zhong S, and Shen L (2014) Post-transcriptional regulation by miR-137 underlies the low abundance of CAR and low rate of bilirubin clearance in neonatal mice. Life Sci 107:8-13.

Dayoub R, Thasler WE, Bosserhoff AK, Singer T, Jauch KW, Schlitt HJ, and Weiss TS (2006) Regulation of polyamine synthesis in human hepatocytes by hepatotrophic factor augmenter of liver regeneration. Biochem Biophys Res Commun 345:181-187.

de Boussac H, Ratajewski M, Sachrajda I, Köblös G, Tordai A, Pulaski L, Buday L, Váradi A and Arányi T (2010) The ERK1/2-hepatocyte nuclear factor $4 \alpha$ axis regulates human ABCC6 gene expression in hepatocytes. J Biol Chem 285:22800-22808.

De Mattia E, Cecchin E, Roncato R, and Toffoli G (2016) Pregnane X receptor, constitutive androstane receptor and hepatocyte nuclear factors as emerging players in cancer precision medicine. Pharmacogenomics 17:1547-1571.

Ding X, Lichti K, Kim I, Gonzalez FJ, and Staudinger JL (2006) Regulation of constitutive androstane receptor and its target genes by fasting, cAMP, hepatocyte nuclear factor alpha, and the coactivator peroxisome proliferator-activated receptor gamma coactivator-1alpha. J Biol Chem 281:26540-26551.

Ding X and Staudinger JL (2005) The ratio of constitutive androstane receptor to pregnane X receptor determines the activity of guggulsterone against the Cyp2b10 promoter. J Pharmacol Exp Ther 314:120-127.

Ebert B, Kisiela M, and Maser E (2016) Transcriptional regulation of human and murine shortchain dehydrogenase/reductases (SDRs) - an in silico approach. Drug Metab Rev 48:183-217. Elcombe CR, Peffer RC, Wolf DC, Bailey J, Bars R, Bell D, Cattley RC, Ferguson SS, Geter D, Goetz A, et al. (2014) Mode of action and human relevance analysis for nuclear receptormediated liver toxicity: a case study with phenobarbital as a model constitutive androstane receptor (CAR) activator. Crit Rev Toxicol 44:64-82.

Faucette SR, Sueyoshi T, Smith CM, Negishi M, Lecluyse EL, and Wang H (2006) Differential regulation of hepatic CYP2B6 and CYP3A4 genes by constitutive androstane receptor but not pregnane X receptor. J Pharmacol Exp Ther 317:1200-1209.

Fu D, Mitra K, Sengupta P, Jarnik M, Lippincott-Schwartz J, and Arias IM (2013) Coordinated elevation of mitochondrial oxidative phosphorylation and autophagy help drive hepatocyte polarization. Proc Natl Acad Sci USA 110:7288-7293.

Gao J and Xie W (2012) Targeting xenobiotic receptors PXR and CAR for metabolic diseases. Trends Pharmacol Sci 33:552-558.

Gonzalez FJ (2008) Regulation of hepatocyte nuclear factor $4 \alpha$-mediated transcription. Drug Metab Pharmacokinet 23:2-7. 
Goodwin B, Moore LB, Stoltz CM, McKee DD, and Kliewer SA (2001) Regulation of the human CYP2B6 gene by the nuclear pregnane X receptor. Mol Pharmacol 60:427-431.

Handschin C and Meyer UA (2003) Induction of drug metabolism: the role of nuclear receptors. Pharmacol Rev 55:649-673.

Ichikawa T, Horie-Inoue K, Ikeda K, Blumberg B, and Inoue S (2006) Steroid and xenobiotic receptor SXR mediates vitamin K2-activated transcription of extracellular matrix-related genes and collagen accumulation in osteoblastic cells. J Biol Chem 281:16927-16934.

Ismail T, Howl J, Wheatley M, McMaster P, Neuberger JM, and Strain AJ (1991) Growth of normal human hepatocytes in primary culture: effect of hormones and growth factors on DNA synthesis. Hepatology 14:1076-1082.

Itoh M, Nakajima M, Higashi E, Yoshida R, Nagata K, Yamazoe Y, and Yokoi T (2006) Induction of human CYP2A6 is mediated by the pregnane $\mathrm{X}$ receptor with peroxisome proliferatoractivated receptor-gamma coactivator 1alpha. J Pharmacol Exp Ther 319:693-702.

Kakizaki S, Yamazaki Y, Kosone T, Horiguchi N, Sohara N, Sato K, Takagi H, Yoshinari K, and Mori M (2007) Gene expression profiles of drug-metabolizing enzymes and transporters with an overexpression of hepatocyte growth factor [published correction appears in Liver Int (2007) 27:733]. Liver Int 27:109-119.

Kamiyama Y, Matsubara T, Yoshinari K, Nagata K, Kamimura H, and Yamazoe Y (2007) Role of human hepatocyte nuclear factor $4 \alpha$ in the expression of drug-metabolizing enzymes and transporters in human hepatocytes assessed by use of small interfering RNA. Drug Metab Pharmacokinet 22:287-298.

Kandel BA, Thomas M, Winter S, Damm G, Seehofer D, Burk O, Schwab M, and Zanger UM (2016) Genomewide comparison of the inducible transcriptomes of nuclear receptors CAR, PXR and PPAR $\alpha$ in primary human hepatocytes. Biochim Biophys Acta 1859:1218-1227.

Kassambara A, Rème T, Jourdan M, Fest T, Hose D, Tarte K, and Klein B (2015) GenomicScape: an easy-to-use web tool for gene expression data analysis. Application to investigate the molecular events in the differentiation of B cells into plasma cells. PLOS Comput Biol 11:e1004077.

Katsura N, Ikai I, Mitaka T, Shiotani T, Yamanokuchi S, Sugimoto S, Kanazawa A, Terajima H, Mochizuki Y, and Yamaoka Y (2002) Long-term culture of primary human hepatocytes with preservation of proliferative capacity and differentiated functions. J Surg Res 106:115-123.

Kawamura A, Yoshida Y, Kimura N, Oda H, and Kakinuma A (1999) Phosphorylation/dephosphorylation steps are crucial for the induction of CYP2B1 and CYP2B2 gene expression by phenobarbital. Biochem Biophys Res Commun 264:530-536.

Khetani SR and Bhatia SN (2008) Microscale culture of human liver cells for drug development. Nat Biotechnol 26:120-126.

Koike C, Moore R, and Negishi M (2007) Extracellular signal-regulated kinase is an endogenous signal retaining the nuclear constitutive active/androstane receptor (CAR) in the cytoplasm of mouse primary hepatocytes. Mol Pharmacol 71:1217-1221.

Komposch K and Sibilia M (2016) EGFR signaling in liver diseases. Int J Mol Sci (2016) 17:30. DOI: $10.3390 /$ ijms 17010030

Lamba V, Ghodke Y, Guan W, and Tracy TS (2014) microRNA-34a is associated with expression of key hepatic transcription factors and cytochromes P450. Biochem Biophys Res Commun 445: 404-411.

Lambert CB, Spire C, Claude N, and Guillouzo A (2009) Dose- and time-dependent effects of phenobarbital on gene expression profiling in human hepatoma HepaRG cells. Toxicol Appl Pharmacol 234:345-360.

Lauschke VM, Hendriks DF, Bell CC, Andersson TB, and Ingelman-Sundberg M (2016a) Novel 3D culture systems for studies of human liver function and assessments of the hepatotoxicity of drugs and drug candidates. Chem Res Toxicol 29:1936-1955.

Lauschke VM, Vorrink SU, Moro SM, Rezayee F, Nordling Å, Hendriks DF, Bell CC, SisonYoung R, Park BK, Goldring CE, et al. (2016b) Massive rearrangements of cellular MicroRNA signatures are key drivers of hepatocyte dedifferentiation. Hepatology 64:1743-1756.

Lehmann JM, McKee DD, Watson MA, Willson TM, Moore JT, and Kliewer SA (1998) The human orphan nuclear receptor PXR is activated by compounds that regulate CYP3A4 gene expression and cause drug interactions. J Clin Invest 102:1016-1023.

Li D, Mackowiak B, Brayman TG, Mitchell M, Zhang L, Huang SM, and Wang H (2015) Genome-wide analysis of human constitutive androstane receptor (CAR) transcriptome in wildtype and CAR-knockout HepaRG cells. Biochem Pharmacol 98:190-202.

Li L, Sinz MW, Zimmermann K, and Wang H (2012) An insulin-like growth factor 1 receptor inhibitor induces CYP3A4 expression through a pregnane $\mathrm{X}$ receptor-independent, noncanonical constitutive androstane receptor-related mechanism. J Pharmacol Exp Ther 340:688-697.

Lin C, Ballinger KR, and Khetani SR (2015) The application of engineered liver tissues for novel drug discovery. Expert Opin Drug Discov 10:519-540.

Lin C and Khetani SR (2016) Advances in engineered liver models for investigating drug-induced liver injury. BioMed Res Int 2016:1829148.

Lynch C, Pan Y, Li L, Heyward S, Moeller T, Swaan PW, and Wang H (2014) Activation of the constitutive androstane receptor inhibits gluconeogenesis without affecting lipogenesis or fatty acid synthesis in human hepatocytes. Toxicol Appl Pharmacol 279:33-42.

Maglich JM, Parks DJ, Moore LB, Collins JL, Goodwin B, Billin AN, Stoltz CA, Kliewer SA, Lambert MH, Willson TM, et al. (2003) Identification of a novel human constitutive androstane receptor (CAR) agonist and its use in the identification of CAR target genes. J Biol Chem 278: 17277-17283.

Maglich JM, Stoltz CM, Goodwin B, Hawkins-Brown D, Moore JT, and Kliewer SA (2002) Nuclear pregnane $\mathrm{x}$ receptor and constitutive androstane receptor regulate overlapping but distinct sets of genes involved in xenobiotic detoxification. Mol Pharmacol 62:638-646.

Moore LB, Parks DJ, Jones SA, Bledsoe RK, Consler TG, Stimmel JB, Goodwin B, Liddle C, Blanchard SG, Willson TM, et al. (2000) Orphan nuclear receptors constitutive androstane receptor and pregnane $\mathrm{X}$ receptor share xenobiotic and steroid ligands. J Biol Chem 275 : $15122-15127$.
Mutoh S, Osabe M, Inoue K, Moore R, Pedersen L, Perera L, Rebolloso Y, Sueyoshi T, and Negishi M (2009) Dephosphorylation of threonine 38 is required for nuclear translocation and activation of human xenobiotic receptor CAR (NR1I3). J Biol Chem 284:34785-34792.

Mutoh S, Sobhany M, Moore R, Perera L, Pedersen L, Sueyoshi T, and Negishi M (2013) Phenobarbital indirectly activates the constitutive active androstane receptor (CAR) by inhibition of epidermal growth factor receptor signaling. Sci Signal 6:ra31.

Negishi M (2017) Phenobarbital meets phosphorylation of nuclear receptors. Drug Metab Dispos 45:532-539.

Oladimeji P, Cui H, Zhang C, and Chen T (2016) Regulation of PXR and CAR by protein-protein interaction and signaling crosstalk. Expert Opin Drug Metab Toxicol 12:997-1010.

Ooe H, Kon J, Oshima H, and Mitaka T (2009) Thyroid hormone is necessary for expression of constitutive androstane receptor in rat hepatocytes. Drug Metab Dispos 37:1963-1969.

Osabe M, Sugatani J, Takemura A, Kurosawa M, Yamazaki Y, Ikari A, and Miwa M (2009) Upregulation of CAR expression through Elk-1 in HepG2 and SW480 cells by serum starvation stress. FEBS Lett 583:885-889.

Pascussi JM, Busson-Le Coniat M, Maurel P, and Vilarem MJ (2003) Transcriptional analysis of the orphan nuclear receptor constitutive androstane receptor (NR1I3) gene promoter: identification of a distal glucocorticoid response element. Mol Endocrinol 17:42-55.

Pascussi JM, Gerbal-Chaloin S, Duret C, Daujat-Chavanieu M, Vilarem MJ, and Maurel P (2008) The tangle of nuclear receptors that controls xenobiotic metabolism and transport: crosstalk and consequences. Annu Rev Pharmacol Toxicol 48:1-32.

Petkov PM, Zavadil J, Goetz D, Chu T, Carver R, Rogler CE, Bottinger EP, Shafritz DA, and Dabeva MD (2004) Gene expression pattern in hepatic stem/progenitor cells during rat fetal development using complementary DNA microarrays. Hepatology 39:617-627.

Pichard L, Raulet E, Fabre G, Ferrini JB, Ourlin JC, and Maurel P (2006) Human hepatocyte culture. Methods Mol Biol 320:283-293.

Shizu R, Osabe M, Perera L, Moore R, Sueyoshi T, and Negishi M (2017) Phosphorylated nuclear receptor CAR forms a homodimer to repress its constitutive activity for ligand activation. $\mathrm{Mol}$ Cell Biol 37:e0649-16.

Sueyoshi T, Kawamoto T, Zelko I, Honkakoski P, and Negishi M (1999) The repressed nuclear receptor CAR responds to phenobarbital in activating the human CYP2B6 gene. J Biol Chem 274:6043-6046.

Treindl F, Ruprecht B, Beiter Y, Schultz S, Döttinger A, Staebler A, Joos TO, Kling S, Poetz O, Fehm T, et al. (2016) A bead-based western for high-throughput cellular signal transduction analyses. Nat Commun 7:12852.

Tzameli I, Pissios P, Schuetz EG, and Moore DD (2000) The xenobiotic compound 1,4-bis[2-(3,5dichloropyridyloxy)]benzene is an agonist ligand for the nuclear receptor CAR. Mol Cell Biol 20:2951-2958.

Ueda A, Hamadeh HK, Webb HK, Yamamoto Y, Sueyoshi T, Afshari CA, Lehmann JM, and Negishi M (2002) Diverse roles of the nuclear orphan receptor CAR in regulating hepatic genes in response to phenobarbital. Mol Pharmacol 61:1-6.

Vető B, Bojcsuk D, Bacquet C, Kiss J, Sipeki S, Martin L, Buday L, Bálint BL, and Arányi T (2017) The transcriptional activity of hepatocyte nuclear factor 4 alpha is inhibited via phosphorylation by ERK1/2. PLoS One 12:e0172020.

Vinci B, Duret C, Klieber S, Gerbal-Chaloin S, Sa-Cunha A, Laporte S, Suc B, Maurel P, Ahluwalia A, and Daujat-Chavanieu M (2011) Modular bioreactor for primary human hepatocyte culture: medium flow stimulates expression and activity of detoxification genes. Biotechnol J 6:554-564

Vorrink SU, Ullah S, Schmidt S, Nandania J, Velagapudi V, Beck O, Ingelman-Sundberg M, and Lauschke VM (2017) Endogenous and xenobiotic metabolic stability of primary human hepatocytes in long-term 3D spheroid cultures revealed by a combination of targeted and untargeted metabolomics. FASEB J 31:2696-2708.

Wada T, Gao J, and Xie W (2009) PXR and CAR in energy metabolism. Trends Endocrinol Metab 20:273-279.

Wagner M, Halilbasic E, Marschall HU, Zollner G, Fickert P, Langner C, Zatloukal K, Denk H, and Trauner M (2005) CAR and PXR agonists stimulate hepatic bile acid and bilirubin detoxification and elimination pathways in mice. Hepatology 42:420-430.

Wang YM, Ong SS, Chai SC, and Chen T (2012) Role of CAR and PXR in xenobiotic sensing and metabolism. Expert Opin Drug Metab Toxicol 8:803-817.

Xie W, Barwick JL, Simon CM, Pierce AM, Safe S, Blumberg B, Guzelian PS, and Evans RM (2000) Reciprocal activation of xenobiotic response genes by nuclear receptors SXR/PXR and CAR. Genes Dev 14:3014-3023.

Yang H and Wang H (2014) Signaling control of the constitutive androstane receptor (CAR). Protein Cell 5:113-123.

Yasujima T, Saito K, Moore R, and Negishi M (2016) Phenobarbital and insulin reciprocate activation of the nuclear receptor constitutive androstane receptor through the insulin receptor. $J$ Pharmacol Exp Ther 357:367-374.

Zhou J, Febbraio M, Wada T, Zhai Y, Kuruba R, He J, Lee JH, Khadem S, Ren S, Li S, et al (2008) Hepatic fatty acid transporter Cd36 is a common target of LXR, PXR, and PPARgamma in promoting steatosis. Gastroenterology 134:556-567.

Zhou J, Zhai Y, Mu Y, Gong H, Uppal H, Toma D, Ren S, Evans RM, and Xie W (2006) A novel pregnane $\mathrm{X}$ receptor-mediated and sterol regulatory element-binding protein-independent lipogenic pathway. J Biol Chem 281:15013-15020.

Address correspondence to: Martine Daujat-Chavanieu, Institute of Regenerative Medicine and Biotherapy INSERM U1183, Hopital St Eloi, 80, Avenue Augustin Fliche, 34295 Montpellier, France. E-mail: martine.daujat@inserm.fr 